\title{
Effects of mesoscale eddies on behavior of an oil spill resulting from an accidental deepwater blowout in the Black Sea: an assessment of the environmental impacts
}

\author{
Konstantin A Korotenko ${ }^{\text {Corresp. } 1}$ \\ ${ }^{1}$ Physical Oceanography, Shirshov Institute of Oceanology, RAS, Moscow, Russian Federation \\ Corresponding Author: Konstantin A Korotenko \\ Email address: kkorotenko@gmail.com
}

Because of the environmental sensitivity of the Black Sea, as a semi-enclosed sea, any subsea oil spills can cause destructive impacts on the marine environment and beaches. Employing numerical modeling as a prediction tool is one of the most efficient methods to understand oil spill behavior under various environmental forces. In this regard, a coupled circulation/deepsea oil spill model has been applied to the Black Sea to address the behavior of the oil plume resulting from a representative hypothetical deepwater blowout. With climatological forcing, the hydrodynamic module based on DieCAST ocean circulation model realistically reproduces seasonally-varying circulation from basin-scale dominant structures to meso- and sub-mesoscale elements. The oil spill model utilizes pre-calculated DieCAST thermo-hydrodynamic fields and uses a Lagrangian tracking algorithm for predicting the displacement of a large number of seeded oil droplets, the sum of which forms the rising oil plume resulting from a deepwater blowout. Basic processes affecting the transport, dispersal of oil and its fate in the water column are included in the coupled model. A hypothetical oil source was set at the bottom, at the northwestern edge of the Shatsky Ridge in the area east of the Crimea peninsula where the oil exploration/ development is likely to be planned. Goals of the study are to elucidate the behavior of the subsea oil plume and assess scales of contamination of marine environment and coastlines resulting from potential blowouts. The two 20-day scenarios with the oil released by a hypothetical blowout were examined to reveal combined effects of the basin-scale current, near-shore eddies, and winds on the behavior of the rising oil plume and its spreading on the surface. A special attention is paid to the Caucasian near-shore anticyclonic eddy which is able to trap surfacing oil, detain it and deliver it to shores. The length of contaminated coastlines of vulnerable Crimean and Caucasian coasts are assessed along with amounts of oil beached and deposited. 
1 Effects of mesoscale eddies on the behavior of an oil spill resulting from an

2 accidental deepwater blowout in the Black Sea: an assessment of

3 environmental impacts

4 Konstantin Alex Korotenko

5 Physical Oceanography, Shirshov Institute of Oceanology, Moscow, Russian Federation

6

7 Corresponding Author:

8 Konstantin Korotenko

936 Nakhimovskiy Prospect, Moscow, 117997, Russian Federation

10 Email address: kkorotenko@gmail.com

11 


\section{ABSTRACT}

13 Because of the environmental sensitivity of the Black Sea, as a semi-enclosed sea, any subsea oil

14 spills can cause destructive impacts on the marine environment and beaches. Employing

15 numerical modeling as a prediction tool is one of the most efficient methods to understand oil

16 spill behavior under various environmental forces. In this regard, a coupled circulation/deepsea

17 oil spill model has been applied to the Black Sea to address the behavior of the oil plume

18 resulting from a representative hypothetical deepwater blowout. With climatological forcing, the

19 hydrodynamic module based on DieCAST ocean circulation model realistically reproduces seasonally-varying circulation from basin-scale dominant structures to meso- and sub-mesoscale elements. The oil spill model utilizes pre-calculated DieCAST thermo-hydrodynamic fields and uses a Lagrangian tracking algorithm for predicting the displacement of a large number of seeded oil droplets, the sum of which forms the rising oil plume resulting from a deepwater blowout. Basic processes affecting the transport, dispersal of oil and its fate in the water column are included in the coupled model. A hypothetical oil source was set at the bottom, at the northwestern edge of the Shatsky Ridge in the area east of the Crimea peninsula where the oil exploration/ development is likely to be planned. Goals of the study are to elucidate the behavior of the subsea oil plume and assess scales of contamination of marine environment and coastlines resulting from potential blowouts. The two 20-day scenarios with the oil released by a hypothetical blowout were examined to reveal combined effects of the basin-scale current, nearshore eddies, and winds on the behavior of the rising oil plume and its spreading on the surface. A special attention is paid to the Caucasian near-shore anticyclonic eddy which is able to trap surfacing oil, detain it and deliver it to shores. The length of contaminated coastlines of the vulnerable Crimean and Caucasian coasts are assessed along with amounts of oil beached and deposited.

\section{INTRODUCTION}

Offshore exploration and development of oil resources as well as the industrial exploitation of oil reserves pose a great threat to the marine environment and venerable beaches. For the semienclosed Black Sea, such activity can result in lasting damage to the environment and fragile 40 habitat.

41 These studies were undertaken to improve understanding of how the mesoscale circulation

42 of the Black Sea along with its basin-scale Rim Current might effect on processes of the 
43 transport and dispersal of oil spilled by a deepwater oil well as the result of its accidental

44 damage. Employing numerical simulation is one of the easiest and most effective prediction tools

45 for understanding the oil spill behavior under various environmental forces. The knowledge of

46 the scale of a possible disaster allows the coastguard efforts better focusing to identify

47 preliminary steps towards such an event, decreasing the lead time available for response and 48 mitigation efforts.

49 Potentially, exploration and development of oil are associated with contamination of the 50 environment as a result of possible accidental spills. Such a problem became too apparent in 51 spring 2010, when about 578,000 tons (3,635,000 barrels) of oil was released into the Gulf of Mexico during the almost 3-month catastrophic deepwater blowout following the tragic Deepwater Horizon (DWH) oil rig explosion on April 20, 2010 (Liu, MacFadyen \& Weisberg, 2011; Sokolofsky, Adams \& Sherwood, 2011; North et al., 2011; Lavrova \& Kostianoy, 2011; Paris et al., 2012; Hénaff et al., 2012, Korotenko et al., 2013; Dietrich et al., 2014; Fingas, 2017). According to the satellite images, the spill has directly impacted $180,000 \mathrm{~km}^{2}$ of the Gulf of Mexico (GoM). However the anticipated disastrous downstream effects did not materialize and, fortunately, no oil related to the DWH source was not reported along the South Florida coastal areas or in the Atlantic Ocean (www.nytimes.com/interactive/2010/05/01/us/20100501-oil-spilltracker.html).

The DWH accident presented the challenge to oil spill modelers to realistically predict the behavior of oil spilled by a deepwater blowout (Camilli et al., 2010; Paris et al., 2012). Many efforts were undertaken to improve numerical models describing the structure of an oil plume rising from a deepwater oil well, the formation and movement of an oil slick on the ocean surface as result of surfacing oil (Liu, Weisberg \& Zheng, 2011; Sokolofsky, Adams \& Sherwood, 2011; North et al., 2011 Korotenko et al., 2013). A well-validated ocean circulation model coupled with an oil spill model, in addition to the implementation of specific algorithms describing the fate of oil, should realistically predict the behavior and transformation of the oil plume (Mariano et al., 2011; Korotenko et al., 2013; North et al., 2015). In modeling oil slicks, an important issue is to drive the computation model with realistic winds since misrepresenting the details of the local wind forcing leads to errors in predicting the oil slick behavior and the subsequent distribution of oil concentration (Caratelli, Dentale \& Reale, 2011; Le Hanaff et al., 2012, Korotenko et al., 2013). 
The catastrophe in the GoM has revealed a very serious threat posed to the marine environment by exploration and development of deepwater oil resources, and despite best efforts to prevent such disastrous events, they seem to be inevitable due to a number of reasons, whether man-made or natural. In this connection, the growing activity in different parts of the oceanic shelf raises a serious environmental concern regarding possible consequences for water bodies where drilling is going on or planned. The semi-enclosed Black Sea suffers from strong ecological disequilibria caused by pollution arising from many contaminants, atmospheric deposition and occasional accidents at the sea. Among the major contaminants, oil residues have a particular concern. In the past, accidental oil spills resulting from collisions and groundings of oil tankers as well as from accidental spills at oil terminals and damages to coastal pipelines have the major potential environmental impact (Stoyanov, Dorogan \& Jelescu, 1999; Korotenko, Bowman \& Dietrich, 2003). In the last decade, intense explorations and developments of deepwater oil resources discovered on the continental shelf of the Black Sea pose a greater threat and risks for the marine environment and coastline than was previously recognized (Robinson et al., 1996; Ergün, Dondurur \& Cifci, 2002; Egorov et al., 2003; Akhmetzhanov, 2007; Körber et al., 2014).

According to recent observations, many oil/gas seepage areas were discovered along the Bulgarian continental shelf and more than 6,000 individual seeps are identified offshore Bulgaria. Some ten thousand of seepage are reported to exist within the Georgian shelf (Körber et al., 2014). Several areas of active gas venting and oil seeps are also discovered in Romanian, Ukrainian and Turkish waters. More than 500 gas plumes are documented by echo-sounding along the shelf break of the Western and North-Western part of the Black Sea. Abundant gas seepage have been found around the edge of the basin in water depth down to $800 \mathrm{~m}$ along the shelf break and active faults in the shelf areas, especially along the frontal lines of Balkanides, Crimea and Great Caucasus, in the northwestern shelf where several oil and gas fields in the Bulgarian, Ukrainian and Romanian shelves are exploiting (Offshore Energy Today, 2018). To confirm the Black Sea's reserves, recently an ultra-deepwater well was drilled off the coast of Turkey (Ergün, Dondurur \& Cifci, 2002). It was performed under the framework of exploration plans and allowed Turkish experts estimating the Black Sea recoverable reserves of crude oil that contains about ten billion barrels. Oil and gas reserves in Georgian, Russian and Ukrainian offshore sectors are also planned to develop in near future to boost the oil production in this 
105 region. In this connection, an important issue for environmentalists now is to control all activities

106 related to offshore oil and gas exploration in the Black Sea and assessing the risks posed by these

107 activities to the marine ecosystem. It is worthwhile to mention the EU EMODNET Black Sea

108 Checkpoint monitoring system (EMODNET, 2018) in the framework of which the sub-system

109 "Oil Platform Leaks" aims to monitor oil spills over the Black Sea. This sub-system provides oil

110 spill trajectory monitoring and assessments of environmental and coastal impacts. Another

111 monitoring system that also should be mentioned and being of relevance for the study presented

112 below, is the "MyOcean" (Zodiatis et al., 2012) providing identification of the exact location of

113 the spill, predicting of the direction of the slick drift and its final location as well as arrival time,

114 etc. Such predictions can greatly assist the agencies, related to marine safety, for reducing the

115 impact on the marine environment that may arise from pollution incidents.

116 In the presented work, the attention was focused on the northeastern part of the Black Sea

117 because together with intensive oil drillings on shelves of Turkey, Romania, Ukraine, and

118 Georgia that have already started, there are wider plans to start exploration offshore deepwater

119 oil drilling in the Russian sector of the Black Sea in the region of Shatsky Ridge where offshore

120 oil-rich deposits were also discovered (Laverov, 2003).

121 Figure 1 shows the Black Sea bottom topography and composite (obtained in different

122 research cruises) map of discovered offshore gas and oil resources (Robinson et al., 1996; Ergün,

123 Dondurur \& Cifci, 2002; Egorov et al., 2003; Akhmetzhanov et al., 2003; Körber et al., 2014).

124 The structure of the cyclonic basin-scale circulation along the Caucasian and Crimean coasts is

125 well investigated and even rough estimations reveal that the serious environmental risks may

126 arise as the result of possible accidents during offshore oil exploration and development in this

127 region of Black Sea.

128 Major anthropogenic incidents, when oil was spilled at the sea surface or brought there from

129 deepsea, often resulted in the formation of massive oil slicks, extending for hundreds of

130 kilometers. In such cases, it is impossible to save the entire coastline. Therefore, the protection

131 plans should focus on the most important and vulnerable shorelines.

132 Being effective prediction tools, numerical simulations widely used to study the behavior of

133 oil spills of different origin. It should be emphasized that despite many efforts were undertaken

134 for prediction transport and dispersal of oil pollution in the Black Sea, by now, none of the oil

135 spill models has been developed for predicting the behavior of deepwater oil spills and their 
136 impact on the Black Sea marine environment and coasts. In this regard, here, a proposed coupled

137 circulation/oil spill model was elaborated especially to address the transport and behavior of the

138 3-D structure of a rising oil plume resulting from a representative hypothetical deepwater oil

139 blowout in the Black Sea.

140 The present work is focused on 3-D structure and evolution of a hypothetical deepwater oil

141 spill, taking into account the formation of the plume during its rising from a hypothetical

142 wellhead and subsequent spreading on the sea surface. The paper is also addresses

143 contamination of the marine environment and beaches of the Black Sea resulting from the plume

144 development transport. In deep waters, the movement and fate of a multiphase plume is governed

145 by the gas-oil separation process, rising velocity as well as background currents and

146 stratification, while, at the subsurface layer, the plume evolution and its fate experiences the

147 influence of currents induced by local winds, Stokes drift and physicochemical processes which

148 change the oil properties. Note that the gas-oil separation process is not considered in the paper,

149 it is substituted by a simplified parameterization. A special attention is paid to effects of

150 mesoscale structures of the Black Sea in synergy with basin-scale circulation on the spreading of

151 oil pollution.

\section{REGION OF INTEREST}

153 The study is focused on the region adjoining the northern Caucasian and Crimea coasts where

154 potential pollution of vulnerable beaches might happen as result of the exploratory deepwater oil

155 drilling in the area over the northwestern edge of the Shatsky Ridge (Fig. 1). The structure of the

156 Black Sea circulation, in this area, is very complex and contains major elements from basin-

157 scales to mesoscales and even sub-mesoscale structures. Figure 2 presents a composite pattern of

158 surface circulation structure of the Black Sea based on historical measurements and satellite data

159 (e.g., (Oguz et al., 1993; Krivosheya et al., 2001). Basically, the structure is composed of a

160 seasonally varying (stronger in winter and weaker in summer) the cyclonic basin-scale Rim

161 Current (RC) surrounded by numerous near-shore anticyclonic eddies (NAEs) trapped between

162 the RC and the continental shelf. Direct observations based on surface buoys (Zhurbas et al.,

163 2004, Poulain et al., 2005) and ADCP measurements (Oguz \& Besiktepe, 1999) in the upper 100

$164 \mathrm{~m}$ have obtained current velocity of about $0.4-0.5 \mathrm{~m} \mathrm{~s}^{-1}$, occasionally increasing up to $1.0 \mathrm{~m} \mathrm{~s}^{-1}$

165 along the axis of the RC jet. As to deep and intermediate layers, deeper $250 \mathrm{~m}$, i.e., under the

166 RC, as was revealed from drifter tracks (Zatsepin et al., 2003, Korotaev, Oguz \& Riser, 2006) 
167 and ADCP measurements (Ostrovskii et al., 2013), the current velocity gradually decreased 168 reaching $0.04-0.02 \mathrm{~m} \mathrm{~s}^{-1}$ near the bottom.

169 A use of autonomous floats allowed providing to Korotaev, Oguz \& Riser, 2006 a clear 170 evidence for well-pronounced currents and an organized flow structure at intermediate $(750 \mathrm{~m})$ 171 and deep (1550 m) layers. It was discovered in contrast to prior assumptions of a rather weak 172 deep circulation of the Black Sea. As the observations also showed, the magnitudes of 173 intermediate and deep currents reached as much as $0.05 \mathrm{~m} \mathrm{~s}^{-1}$ at $1550 \mathrm{~m}$.

174 Note that not all structures presented in Fig. 2 occur at the same time; nevertheless they are 175 very persistent features of the BS. Observations showed that the NAEs have a preponderance to 176 form during summer and autumn when the RC became weak and unstable. Typically, NAEs 177 have diameter $\sim 30-60 \mathrm{~km}$ and their shape is close to circular After their formation due to 178 headland eddy shedding or from baroclinic instabilities, most NAEs remain trapped between the coast and the RC, and "roll" along the coast like "lubrication eddies" in the same direction as the RC (Korotenko et al., 2010).

181 The Caucasian near-shore anticyclonic eddies (CNAEs) periodically appear in the area 182 between Sukhumi and Sochi, preferentially in winter-spring months. Their average lifetime 183 ranges from two to three months. Moving northwestward along the Caucasian coast, the CNAE 184 is often accompanied by a large offshore anticyclonic meander, the RC being shifted into the central part of the eastern basin. The CNAE often interacts with the Kerch anticyclonic eddy, which is also a well-pronounced element of the Black Sea eddy dynamics. An average persistence of this eddy is about 240 days and its mean lifetime as about 80 days (Korotaev et al., 2003). The spring and autumn seasons are revealed to be more favored periods for the presence of the Kerch eddy. The Crimea anticyclonic eddy usually occurs in August-September, its lifetime is about a month.

191 The Sevastopol anticyclonic eddy (SAE) is also among intense and persistent eddies in the 192 Black Sea. The SAE is periodically formed southwest of the Crimea Peninsula by intense 193 vorticity generation over the very steep continental margin at the southern tip of the peninsula.

194 As was observed, winter and summer are most preferred periods for the SAE formation.

195 According to satellite and instrumental observations, the largest SAEs can grow up to 100-150

$196 \mathrm{~km}$ in diameter and its thickness reaches 100-200 m.

\section{METHOD}




\section{Deepsea Oil Spill Model}

199 Accurate predicting the transport, dispersal, and fate of oil plume releasing by a deepwater

200 blowout, description the plume rising toward the sea surface and spreading in the subsurface

201 layer require developing new models with ability to describe major processes affecting oil plume

202 and utilizing field observations obtained during and after an accident. For modeling deepwater

203 oil spills, the Lagrangian particle-tracking method (LPTM) coupled with the low dissipative

204 eddy resolved DieCAST Ocean Circulation Model (Dietrich et al., 1997) was adapted for the

205 Black Sea, the latter being the $(1 / 30)^{\circ}$ horizontal resolution version of the DieCAST (Die2BS)

206 (Korotenko, Bowman \& Dietrich, 2010; Korotenko, 2015).

207 The overall structure of the Deepsea Oil Spill Model (DOSM) is presented in Fig. 3, where

208 oil properties and are geographic data stored in the database in advance. Once a deepwater oil

209 spill accident happens, data such as duration of the spill and its location, oil volume/discharge-

210 rate as well as information on current weather conditions and waves are input into the model.

211 Die2BS has operated ahead of the oil transport model in order to provide the DOSM with

212 necessary hydrodynamic data and parameters. Taking into account a combined effect of winds

213 and waves on the horizontal transport of oil, the superposition of wind and wave drift currents is

214 calculated.

215 Generally, the procedure predicting oil plume behavior is divided into two parts: i) pre-

216 calculation of currents, $\vec{V}$, temperature, $T$, and salinity, $S$, and diffusion coefficients, $K_{H}$ and $K_{Z}$

217 with a use of the Die2BS hydrodynamic model; ii) applying computed mean $\vec{V}, T, S, K_{H}$, and $K_{Z}$

218 and calculated terminal velocity (see below) for each oil droplet to describe movement of

219 individual oil droplets, the sum of which constitutes the oil plume; and iii) simulating processes

220 of rising oil droplets from the deepwater wellhead, their advection, diffusion, dispersion,

221 biodegradation, and dissolution in the water.

222 Algorithms for oil evaporation and decomposition (due to biochemical and physical

223 degradation) are incorporated in a special ancillary module, which compares the current model

224 time with the 'half-life' time assigned a priory to each droplet (Korotenko, 2010, 2016). A

225 droplet is considered as lost if the current time exceeds "half-life' time assigned to the droplet.

226 Note that only those droplets that occurred within the subsurface 'evaporation layer' $\left(\mathrm{z}_{\mathrm{ev}} \sim 0.1 \mathrm{~m}\right)$

227 experience decay due to evaporation, while disintegration and dispersion may effect on all

228 droplets occurred below $z_{\mathrm{ev}}$. In other words, weathering module, shown in Fig. 3, operates only 
229 at or near to the surface while processes of dissolution, sedimentation, diffusion, etc., are 230 calculated throughout the water column.

231 In the DOSM, oil is presented as a mixture of 8 hydrocarbon groups (Mackay \& McAuliffe, 232 1988) that allows determining evaporation process more accurately. The hydrocarbon groups $\mathrm{C}_{1}$ $233-\mathrm{C}_{8}$ were chosen for light crude oil and adapted for the type oil with characteristics akin to the

234 Black Sea oil. The coupled model was described in detail by Korotenko (2016), below the 235 meaning of main elements and some important equations of the model will be only shortly 236 clarified.

\section{The behavior of a deepsea oil spill in the marine environment}

238 An important issue for deepwater oil spill modeling is to calculate so-called terminal velocity for 239 each oil droplet, i.e., rise velocity of oil droplets which depends on their properties. The terminal 240 velocity, $w_{t}$, of an oil droplet is estimated in the Oil Droplet block (Fig. 3) with a use of the 241 equation for a solid particle (Perry \& Green, 1984):

$$
w_{t}=\left[4 g D_{p}\left(\rho_{p}-\rho\right) /\left(3 \rho C_{D}\right)\right]^{1 / 2}
$$

243 where $\rho_{p}$ is the density of oil, $\rho$ is the density of water, $g$ is the gravitational constant, $D_{p}$ is the

244 diameter of a droplet, and $C_{D}$ is drag coefficient. $C_{D}$ is determined to be equal to $24 / R e_{p}$ when $R e_{p}$

$245<0.1$ or equal to $\left({ }^{24} / R e_{p}\right)\left(1+0.14 R e_{p}^{0.7}\right)$ when $0.1<R e_{p}<1000$. Here $R e_{p}=D_{p} \rho_{p} w_{t} / \mu$ where $\mu$ is

246 the dynamic viscosity. It is apparent from Eq. (1), the more size of an oil droplet and greater

247 density difference between oil and ambient water the more terminal velocity of the droplet.

248 Moving upward with different terminal velocity, the assembly of oil droplets constitutes an ascending subsea plume, in which different droplet will reach the sea surface at different times after the release. Moreover, due to vertical inhomogeneity of horizontal crossflow droplets with different sizes will appear at the sea surface at different locations. Therefore knowledge of the droplet size distribution in a rising oil plume is very important for adequate predicting plume behavior. In other words, determined by the size of droplets and difference between oil and ambient water, terminal velocity of each droplet will fundamentally control when and where the droplets reach the surface and form the surface slick. In practice, various methods are used to estimate the diameters of oil droplets emanating from a blowout, e.g. they can be measured in a laboratory (Masutani \& Adams, 2001) or field (Johansen, 2003) experiments as well as simulated theoretically (Chen \& Yapa, 2007). 
In the model, the size diameter distribution resembling lognormal distribution which

260

261

262

263

264

265

266

267

268

269

270

271

272

273

274

275

276

277

278

279

280

281

282

283

284

285

286

287

288

289 characterized the influence of the natural dispersion on oil transformation was used. Such distribution was obtained in experiments with light crude oil in a wave tank by Li et al. (2008) and contains a very small amount of small droplets ranged from 5 to $80 \mu \mathrm{m}$ and from $500 \mu \mathrm{m}$ to $1 \mathrm{~mm}$ while the vast majority of volume fractions contains droplets ranged from 90 to $400 \mu \mathrm{m}$ with the median value of $300 \mu \mathrm{m}$. For Reynolds numbers picked within the intermediate regime within the range $0.1<R e_{p}<1000$, the largest oil droplets with a diameter of about $1 \mathrm{~mm}$ will rise with a velocity ranged from 0.0031 to $0.074 \mathrm{~m} \mathrm{~s}^{-1}$, respectively. It means that in the case when the oil well located at the depth of $1053 \mathrm{~m}$ (see below) the droplets will take $93.5 \mathrm{~h}$ to reach the sea surface with the former velocity while with the latter velocity it will take only $4 \mathrm{~h}$ (cf. Dasanayaka \& Yapa, 2009; Lardner \& Zodiatis, 2017). The terminal velocity of oil droplet, from the interval from 90 to $400 \mu \mathrm{m}$ (for $R e_{p}=1$ ), ranges from 0.0028 to $0.0059 \mathrm{~m} \mathrm{~s}^{-1}$, respectively. For the calculations, oil with the average density of $830 \mathrm{~kg} \mathrm{~m}^{-3}(\mathrm{API}=39)$ and seawater at 1017 $\mathrm{kg} \mathrm{m}^{-3}$ were used.

It should be emphasized that there are significant differences between processes govern surface oil plumes and those govern plumes resulted from deepwater (depth>300 m) blowouts. Summarizing the observations of deepwater oil/gas plumes in crossflow and stratified water Sokolofsky \& Adams (2005) suggested that the following progression of deepwater plume stages:

1. In the proximity of a deepwater oil source, the oil/gas mixture progresses as a coherent plume.

2. Higher, despite the oil/gas mixture is still behaving as a coherent plume; however, a leakage of fluid entrained from the downstream side of the plume begins because the stripping current velocity overcame the restoring entrainment velocity decreasing with height.

3. Next, above a so-called critical separation height, $h_{S}$, where gas and oil separated, the oil/gas mixture loses its coherency so that entrained water and fine oil droplets are lost downstream while gas and large oil droplets are lost upstream.

4. Finally, the separated mixture of entrained fluid and oil droplets continued to rise in the farfield as a buoyant jet and can be modeled as a single-phase oil plume, initiated at the separation height, $h_{S}$.

Knowing the critical separation height, one can estimate so-called transient time, i.e., the time when gas escaped from the mixed plume. According to observations and model experiments 
290 (Johansen, 2003; Zheng, Yapa \& Chen, 2003; Chen \& Yapa, 2007; Yapa \& Zheng, 1997; Zheng

291 \&, Yapa, 1998), the transient time was estimated to be equal to several seconds, so that after time

292 of the transition, the Lagrangian particle-tracking method can be used to describe the transport

293 and dispersal of oil droplets in the far-field plume.

294 LPTM algorithm used in DOSM

295 Once oil droplets rising from a deepwater oil well appear at the surface, they are moving away

296 from initial surfacing points due to the complex action of surface currents, winds, and waves. To

297 predict the movement of an ensemble of oil droplets, in the model, the displacements of each

298 droplet can be estimated as (Korotenko, 2016):

$299\left(\Delta x_{i}\right)_{j, k}=V_{i, j} \Delta t_{j}+\left(\vartheta_{i}\right)_{j, k}\left(i=1-3 ; j=1,2, \ldots, N_{t} ; k=k_{f}=1,2, \ldots, N_{f} ; f=1,2, \ldots, 8\right)(2)$

300 where $N_{f}$ is the number of droplets within $f$-th hydrocarbon group while $k_{f}$ denotes the $k_{f} t h$

301 droplet within a $f$-th $C$-group. Hereafter for brevity, subscript $f$ was omitted. The displacements

$302\left(\Delta x_{i}\right)_{i, k}$ are determined as a sum of a deterministic part of the droplet displacement due to the

303 mean velocity field, $V_{i, j}$ and a random displacement, $\left(\vartheta_{i}\right)_{i, k}$ due to velocity fluctuations

304 determined the block " $\vec{V}, T, S^{\prime \prime}(\mathbf{F i g} \mathbf{3})$. The term $\left(\Delta x_{i}\right)_{j, k}$ is the displacement of the $k$-th droplet

305 along the axis $x_{i}$ at the $j$-th instant of time. $N_{t}$ denotes the total number of time steps, and $\Delta t$ is

306 the time step. The distribution of the number of particles in $f$ groups depends on the type of oil;

307 it is initially assigned and distributed randomly according to the specification of oil chosen. Each

$308 k$-droplet within a $f$-th group is characterized by size, density, position $X_{i, j, k}$ and its 'half-life'

309 period. The latter, as was said above, was assigned a priori once the droplet was launched.

310 The advective movement within a grid cell is computed with the use of the linear

311 interpolation of the velocity components at a droplet position from 8 nodes of a corresponding

312 Die2BS grid cell at the time step $\Delta t$.

313 To estimate random displacements of each droplet due to sub-grid fluctuations of velocity

314 or, shortly, diffusive jumps of a droplet, $\left(\vartheta_{i}\right)_{j, k}$, different approaches for the horizontal $(i=1,2)$

315 and vertical $(i=3)$ axes were used. For the horizontal axes, so-called 'naive random walk'

316 (NRW) scheme is widely used. In this approach $\left(\vartheta_{i}\right)_{j, k}$ is defined as $\vartheta_{i=} \gamma_{i}\left(2 K_{i, j} \Delta t\right)^{1 / 2}$ (Spaulding,

317 1988; Korotenko, Mamedov \& Mooers, 2001). Here, $\vartheta_{i}$ is a random vector, normally distributed

318 with an averaged value of zero and unit standard deviation. 
To avoid artificial droplet accumulation in layers with weak vertical mixing, for the vertical

320

321

322

323

324

325

326

327

328

329

330

331

332

333

334

335

336

337

338

339

340

341

342

343

344

345

346

347

348

349 axis, so-called 'consistent random walk' (CRW) approach is applied. The latter approach was developed by Visser (1997) who suggested the following formula for estimating vertical droplet's displacement:

$$
\vartheta_{3}=K_{3}^{\prime}(z) \Delta t+\gamma_{3}\left[2 K_{3}\left(z^{*}\right)\right]^{1 / 2}
$$

The CRW approach describes deterministic and diffusive components of vertical displacements. The deterministic component describes a net displacement of the center of mass of droplets toward increasing diffusivity expressed by a local gradient of $K_{3}$, i.e., $K_{3}^{\prime}$. It allows avoiding an artificial accumulation of droplets within layers where vertical diffusivity is low. The vertical diffusivity, $K_{3}$, in the CRW model, is estimated with the use of the diffusivity profile at a vertical coordinate $z^{*}$ shifted from the droplet coordinate $z$ by a small distance $0.5 K_{3}^{\prime}$ (z) $\Delta t$. More details on LPTM algorithms were given in (Korotenko, 2016). Note, however, that this kind of approach is very sensitive to the vertical resolution of the model; for coarse resolution, the effect of the CRW approach on the accumulation of particles/oil droplets would hardly be noticeable. Nevertheless, for the Black Sea, the generalized oil spill model with the CRW approach was used for a future implementation of a fine resolution nested model.

\section{Modeling the deepwater oil blowout}

A hypothetical oil source was set at the bottom, at the site south of the Kerch Strait over the northwestern edge of the Shatsky Ridge at coordinates 443' $\mathrm{N}, 36^{\circ} 36^{\prime}$ E where depth is 1053

m. In Fig. 1, the source was marked by the asterisk inside of the red dot denoted the discovered oil-rich site (Egorov et al., 2003). The blowout lasted 20 days and its discharge rate was set to be constant and equal to 20 metric tons/hour.

Since a plume released from deepwater oil blowout presents, as was pointed above, the oilgas mixture, the latter will split, at some separation height, $h_{S}$, above the bottom, into individual oil droplets and gas bubbles. For an instance, the separation height is equal to $200 \mathrm{~m}$ for bottom current velocity of $0.02 \mathrm{~m} \mathrm{~s}^{-1}$ (Sokolofsky, Adams \& Sherwood, 2011), so that, within the 200$\mathrm{m}$ layer above the bottom, oil droplets are driven by gas bubbles while above $h_{S}$, oil droplets rise with the terminal velocity determined by Eq.1.

The continuous source of oil droplets was mimicked by regular ejection (its period coincides with the oil spill model time step, $\Delta t$ ) of a cloud of droplets. In the oil spill model, 1000 oil droplets were released every $30 \mathrm{~min}$ at the depth of hypothetical blowout. Each droplet 
350 represents a fraction of the mass of released oil, so that each oil droplet will represent one $\mathrm{kg}$ of

351 oil. It gives the initial concentration of oil within the first z-layer above the oil wellhead of

$3521.5 \cdot 10^{-7} \mathrm{~kg} \mathrm{~m}^{-3}$. Note that at the time of each ejection of a droplet cloud, a full set of parameters

353 and properties determining the state of each droplet are assigned (Korotenko et al., 2004).

354 Oil parameters setup

355 Simulating the transport and fate of an oil spill requires a specification of a number of initial

356 parameters. Light crude oil, used in the present work, was chosen to be characterized by the

357 following parameters: oil droplet diameters assigned randomly between $\mathrm{d}_{\min }=2.5 \mu \mathrm{m}$ and $\mathrm{d}_{\max }$

$358=400 \mu \mathrm{m}$; 'half-life times' were chosen as $\operatorname{Tev}_{1}=20 \mathrm{~h}, \operatorname{Tev}_{3}=30 \mathrm{~h}$, and $\operatorname{Tev}_{5}=10 \mathrm{~h}$ for the

359 hydrocarbon groups $\mathrm{C}_{5}, \mathrm{C}_{1}$, and $\mathrm{C}_{3}$, respectively. For the 'long-living' groups, $\mathrm{C}_{2}, \mathrm{C}_{4}, \mathrm{C}_{6}, \mathrm{C}_{7}$, and

$360 \mathrm{C}_{8}$, They all were set to be equal to $\mathrm{Tev}_{4}=250 \mathrm{~h}$ (Korotenko, 2010).

361 For the chosen oil, the percentage mass ratio between $f$-groups was set as follows: $C_{1}=15 \%$;

$362 C_{2}=20 \% ; C_{3}=25 \% ; C_{4}=10 \% ; C_{5}=15 \% ; C_{6}=3 \% ; C_{7}=7 \%$ and $C_{8}=5 \%$. Such ratio means that after

363 oil reaches the sea surface it starts evaporate, with $55 \%$ of total oil mass is expected to be

364 evaporated within a first few days. The evaporation will occur mostly due to light hydrocarbon

365 groups $C_{5}, C_{1}$, and $C_{3}$.

366 Boundary conditions: interaction of oil droplets with shoreline and bottom.

367 The DOSM takes into account the beaching and depositing of oil droplets. In the case when an

368 oil droplet reaches the coastline/bottom, the droplet is considered as beached/deposited one.

369 Vertical boundaries, i.e., the sea surface and bottom are specified by interpolating sea surface

370 level $(\mathrm{z}=0)$ and the bottom to the $\mathrm{x}-\mathrm{y}$ location of each oil droplet. There are two types of vertical

371 boundary conditions are used:

372 1. When a moving droplet passes through the surface or bottom boundaries due to vertical

373 movement then the droplet is returned back to the model domain at a distance equals to the

374 displacement that the droplet exceeds the boundary (the reflecting boundary conditions).

375 2. When a moving droplet numerically jumps over the surface or bottom then the droplet is

376 returned back to the nearest point of the correspondent boundary and coordinates of the droplet

377 are fixed (absorbing boundary conditions).

378 The horizontal boundary condition is a reflecting one if routines keep droplets inside the

379 model domain. If the droplet is on land, the droplet is reflected off the boundary. The integration 
380 time step is chosen on condition that a droplet remains within a correspondent cell. The

381 horizontal boundary condition routine allows droplets to reflect repeatedly within a time step.

382 Based on the abovementioned boundary conditions, in the model, special algorithms are

383 used to define a number of oil droplets beached and deposited. Should a droplet reach the

384 coastline or bottom, it is marked as deposited or beached; its coordinates are fixed at the point

385 where the droplet reached the correspondent boundary. This procedure also accounts for the

386 redistribution of the total oil mass between different oil fractions, i.e., oil evaporated, oil beached

387 and oil deposited. This redistribution of oil is very important for assessing risks and scales of

388 coastline contamination (Korotenko, 2010).

\section{DieCAST circulation model}

390 The principal element of the DOSM is the high-resolution, low dissipative hydrodynamic model

391 Die2BS, shown in Fig. 3 and described in (Korotenko, Bowman \& Deitrich, 2010; Korotenko,

3922015 ; 2017). The computational grid of the model covers the entire Black Sea basin from $27.2^{\circ}$

393 to $42^{\circ} \mathrm{E}$ and from $40.9^{\circ}$ to $46.6^{\circ} \mathrm{N}$, and contains a total of $426 \times 238$ rectangular cells, with 30

394 unevenly spaced levels in the vertical. In the model, the ratio of the horizontal cell dimensions

$395(\Delta \mathrm{X} / \Delta \mathrm{Y})$ is fixed and equal to unity so that square cell dimensions varied only in latitude from

3962.6 to $2.8 \mathrm{~km}$. Since the grid size of Die2BS is significantly less than the first internal baroclinic

397 deformation radius $R \sim 5-20 \mathrm{~km}$ for the Black Sea, the model is able to adequately resolve near-

398 shore mesoscale structures and their variability.

399 The Die2BS was initialized with monthly-averaged temperature and salinity data and forced

400 with climatological surface buoyancy (heat) fluxes, evaporation minus precipitation, monthly

401 winds and river runoff from 31 rivers (Jaoshvily, 2002). At two open boundaries, the exchange

402 through the Bosporus and Kerch Straits are specified as in (Korotenko, 2015). Upon the run of

403 Die2BS, a special nudging data assimilation procedure was launched. In doing so, the surface

404 buoyancy flux was computed by nudging both the temperature and the salinity toward monthly

405 climatology as in Staneva et al. (2001).

406 In the Die2BS, 30 unevenly z-levels were spaced with smaller intervals near the surface for

407 better representation of surface processes, which is crucial for oil spill modeling. These levels are

408 distributed as following: $0,3,6,10,14,21,26,32,39,46,56,66,79,94,112,133,159,190$,

$409227,298,359,432,521,692,837,1014,1230,1493,1645$ and $2221 \mathrm{~m}$. In the model, an

410 unsmoothed ETOPO2 bottom topography is used, and bathymetry is represented as series of 
411 steps, where the vertical velocity is set to zero. The integration time step was chosen to be equal

412 to $6 \mathrm{~min}$. The Die2BS was spun up from rest and with the climatological temperature and

413 salinity. The model was run for a total 23 years with perpetual seasonal forcing, to ensure that

414 the basin averaged kinetic energy, temperature, and basin-scale circulation reach quasi-stationary

415 periodical states. The climatological data used in the DieCAST model has been provided from

416 the CoMSBlack surveys (http://sfp1.ims.metu.edu.tr/texts/database.htm) in the context of the

417 NATO Black Sea project (Staneva et al. 2001).

418 The validation of the circulation model was conducted on the base of satellite images of sea 419 surface temperature and altimetry data, surface current velocities obtained in observations and 420 derived from drifter experiments. Results of the validation were presented in (Korotenko, 2015; $4212016 ; 2017)$.

422 As was shown in (Korotenko 2015; 2017), the Die2BS model realistically reproduces basin423 scale circulation of the Black Sea as cyclonic gyres, the quasi-permanent cyclonic Rim Current, 424 and its seasonal fluctuations; Rossby waves propagating westward across the basin; mesoscale 425 structures as eddies, filaments, up- and downwelling events, mushroom currents, jets

426 (Korotenko, 2015; 2017). High resolution and extremely low horizontal dissipation (horizontal 427 viscosity ranging from 5 to $10 \mathrm{~m}^{2} \mathrm{~s}^{-1}$ ) allow the model to reproduce also numerous anticyclonic 428 eddies and meanders lying between the coast and the RC that is very important from the point of 429 view the transport of contaminations on the continental shelf of the Black Sea.

\section{RESULTS}

\section{Simulation of the Black Sea circulation}

432 Mesoscale features along the Caucasian and Crimean coasts

433 As simulations revealed, a part of the Rim Current jet flowing along the Caucasian coast is 434 periodically displaced offshore. It creates, in the region from Sukhumi to Novorossiysk, large 435 amplitude meanders with favorable conditions for the generation of anticyclonic eddies (Fig. 2). 436 Being a quite persistent structure of this region, the Caucasian near-shore eddies, as was found, 437 often associates with large offshore protrusions of the Rim Current toward the open sea with 438 periodic detachments of the protruded eddies and their absorption by the interior basin 439 circulation. The system "meander-eddy" are often moved along the Caucasian coast and 440 interacted with the Kerch eddy; the latter is also one of the most pronounced features of the 441 Black Sea eddy dynamics. The Kerch and Caucasian eddies, in turn, could either interact with 
442 each other or could be separated from each other by a sharp onshore meander of the Rim 443 Current.

444 Greatly effecting on the local dynamics, the SAE and Crimean coastal anticyclonic eddy 445 appear asynchronously at the western and eastern sides of the Crimean peninsula, respectively. 446 The Crimean eddy is generally attached to the southern tip of the headland while the location of 447 the SAE depending on the local structure of the RC moves with the latter away from the Crimea, 448 mainly southwestward along the topographic slope zone between the northwestern shelf and the 449 western interior.

450 To illustrate the structure of eddy activity in the Black Sea, Fig. 4 presents a pattern of the 451 surface relative vorticity, $\vartheta=\frac{\partial V}{\partial x}-\frac{\partial U}{\partial y}$ on Julian day 80 (hereinafter 'Day') of model year 24. Here, $452 U$ and $V$ are mean velocity horizontal components. The relative vorticity characterizes a measure 453 of rotation at any point of the sea. Counterclockwise rotation means positive or cyclonic 454 vorticity (warm shading) while clockwise rotation denotes negative or anticyclonic vorticity 455 (cold shading). The sign of $\vartheta$ allows identifying mesoscale eddies arising in the sea and, hence, 456 their effect on spreading of pollutants in the Sea. Anticyclonic eddies create convergence zone 457 and, therefore, may accumulate pollution inside of them while cyclonic eddies, on the contrary, 458 reinforce pollution dispersion due to the divergence of circulation.

459 Comparing Fig. 4 with the circulation scheme shown in Fig. 2, one can see a chain of anti460 and cyclonic eddies embedded into the Rim Current including large SAE southwest of the 461 Crimean peninsula and mesoscale eddies along the Anatolian coast of Turkey. Of interest here is 462 anticyclonic activity along the Caucasian and Crimean coasts. As seen, two Caucasian NAEs 463 appeared, by day 80, offshore in the central part of the Caucasian coast. Farther northwest, 464 stretching zone of anticyclonic vorticity crosses the location over the oil source and approaches 465 the well-pronounced Crimean NAE west of Town of Yalta. According to the numerical 466 simulation, in shallow waters, the thickness of NAEs is limited by depth but do not often exceed 467200 meters as they move away from the shore.

$468 \quad$ Figure 5 presents the composite planar plot of the simulated relative vorticity at the surface 469 combined with the vertical section of $\vartheta$ made along $44^{\circ} \mathrm{N}$. As seen, a core of both anticyclonic 470 and cyclonic eddies embedded in the Rim Current spanned down to about $150 \mathrm{~m}$ albeit 471 anticyclonic vorticity penetrates deeper. Light blue color denoting weak negative rotation $(>-20$ $472 \mathrm{rad} \mathrm{wk}^{-1}$ ) extends down to about $700 \mathrm{~m}$ while penetration of the cyclonic vorticity is limited by 
473 130-150 m. In Fig. 5, the section passes through four zones which can be identified as follows :

474 (1) zone 1 crossing the Sevastopol eddy delineated by cyclonic vorticity west of it and

475 anticyclonic vorticity east of it; (2) zone 2 crosses south of the Crimea with strong anticyclonic

476 activity originated by the Yalta NAE; (3) stagnant zone 3 with extremely weak rotation is in the

477 eastern Gyre far from the Rim current and (4) zone 4 where the Rim Current approaching the

478 shore in the region of Novorossiysk-Tuapse creates a system of eddies with different rotation

479 signs. Here again, anticyclonic eddies are found to penetrate noticeably deeper then cyclonic

480 ones. Such results confirmed by field measurements by Zatsepin et al. (2008). Such difference

481 was explained theoretically by a shorter life of cyclonic eddies due to their more intense

482 radiation of Rossby waves than anticyclonic eddies do (McDonald, 1998).

483 Modeling the transport of oil plumes released by a deepwater blowout

484 To investigate a combine impact of the meandering Rim Current and mesoscale eddies on the

485 behavior of an oil plume rising from the bottom, as was mentioned above, the hypothetical

486 deepsea oil source was set at the bottom site (1053 m) east of Crimea (44. $\left.33^{\prime} \mathrm{N}, 36^{\circ} 36^{\prime} \mathrm{E}\right)$ and

487 two scenarios with the 20-day oil blowout experiment were considered for model year 24.

488 The inner structure of rising oil plume

489 Before considering the two scenarios chosen, it is worthwhile to scrutinize an initial stage of the

490 oil plume development. Figure 6A illustrates the inner structure of the oil droplet distribution in

491 the rising oil plume formed in a 24-hour test experiment performed on Day 80. As seen, the

492 rising oil plume consists of four parts: (1) the lower part of the plume, stretching from the bottom

493 to $200 \mathrm{~m}$ above it, presents a narrow column of oil droplets driven by gas bubbles; (2) the second

494 part, stretching from $800 \mathrm{~m}$ above the bottom to about $400 \mathrm{~m}$ below the sea surface, represents

495 an ensemble of oil droplets driven by buoyancy forces with a manifestation of deflection of oil

496 plume by the crossflow. The thickness of this part of the plume is determined by the ratio

497 between the terminal velocity and crossflow in deep layers. An example of the zonal component

498 of subsea crossflow at the depths $200-1000 \mathrm{~m}$ is depicted in the inset (A1); (3) the third part,

499 stretching from about $400 \mathrm{~m}$ below the sea surface to about $50 \mathrm{~m}$ where an influence of the RC

500 becomes essential; and (4) the uppermost part of the plume above the $50 \mathrm{~m}$ where the oil plume

501 experiences a dominant influence of the Rim Current, schematically denoted by RC-arrows in

502 Fig. 6A. 

with ADCP near Port of Novorossiysk (Ostrovskii et al., 2013). As seen, the zonal velocity in the water column does not exceed $0.2 \mathrm{~m} \mathrm{~s}^{-1}$. Note that, for clarity, droplet colors denote depth ranges in the plume, i.e., magenta, red, green and blue correspond to depth ranges 0-250, 250-500, 500750 and $750-1000 \mathrm{~m}$, respectively.

An examination of the simulation results revealed that a great amount of small droplets, which accounts for a large fraction of oil, remains underwater because smaller droplets move upwards much slower than large ones. It means that the horizontal deflection of the smaller

511 droplets by the crossflow is larger than that of large oil droplets. Note that differences in terminal 512 velocity (Eq. 1) of oil droplets with different sizes lead to different times of surfacing and, thus,

513 positions of the oil droplets on the sea surface. According to the simulations, the first particle

514 reached the surface in about $4 \mathrm{~h}$ after the release and its surfacing position was about $200 \mathrm{~m}$

515 north and $150 \mathrm{~m}$ west from the projection of the release point on the sea surface. The small

516 droplets remained underwater for a longer period and, thus, might appear at the sea surface at a

517 larger distance downstream. The horizontal distance that a droplet displaced from the blowout

518 location to the surfacing point is also increasing with time. Figure 6A indicates that for the first

519 day after oil released, the distance that oil droplets traveled on the surface exceeded $15 \mathrm{~km}$ while, 520 at the depth below $250 \mathrm{~m}$, the range of oil droplets did not exceed $1 \mathrm{~km}$.

521 To highlight an influence of the crossflow on oil droplet displacements, Fig. 6B shows the 522 distribution of droplets in the 250-1000 m layer where effect of the RC is inessential and, thus, 523 horizontal intrusions of oil droplets are well-pronounced. Following the crossflow (inset A1), 524 within the layer of 800-700 m, most droplets (blue and green color) have a tendency to move 525 eastward while droplets in the layer above $400 \mathrm{~m}$ are deflected to the west experiencing an influence of the lower part of the RC. In the intermediate depths from 400 to $700 \mathrm{~m}$, oil droplets 527 (red color) are distributed symmetrically due to negligible crossflow at these depths. 528 Interestingly, despite most oil droplets, within the layer of 800-700 m, move to the east, some of 529 them spread also to the west creating horizontal intrusions of about the $1.1 \mathrm{~km}$-long stretch. It 530 should be also recalled that below this layer oil droplets are driven upward by rising gas bubbles 531 due to the parameterization which artificially mimics this process in the DOSM.

532 The inset B1shows profiles of modeled vertical velocity, $V_{3}(z)$ (blue line), and vertical 533 diffusivity, $K_{3}(z)$ (red line), above the location of the oil source. As seen, in the 100-1000 m 
534 layer, $V_{3}(z)$ ranges from $-2 \cdot 10^{-5}$ to $1.8 \cdot 10^{-5} \mathrm{~m} \mathrm{~s}^{-1}$ with positive values below $400 \mathrm{~m}$ and negative 535 values above $400 \mathrm{~m} . K_{3}(z)$ sharply diminishes with depth from $10^{-3} \mathrm{~m}^{2} \mathrm{~s}$ (at $100 \mathrm{~m}$ ) to $10^{-5} \mathrm{~m}^{2} \mathrm{~s}$, so

536 that the noticeable contribution of vertical diffusivity in droplet displacements should be 537 expected in the surface layer of $0-150 \mathrm{~m}$, particularly, in the upper $20 \mathrm{~m}$ where vertical 538 diffusivity can play a significant role in the process of natural dispersion (Dietrich et al., 2014).

\section{Scenario 1}

540 In the first 20-day oil blowout scenario, two comparative experiments for investigating combined 541 effects of winds and the Rim Current on the behavior of the oil slick were performed. The oil 542 spill model was run for model year 24 with the blowout starting from Day 20 (i.e., 20 January).

543 In the first run, average climatic winds were used for the Die2BS spin-up while, for the second 544 run, average climatic winds were substituted by daily NCEP winds averaged for years 1998 5452002.

$546 \quad$ Figure 7 shows the final stage of the distributions of oil concentration, $\log 10(\mathrm{C})$, at the sea 547 surface by Day 40. Figure 7A presents $\log 10(\mathrm{C})$ in the slick formed under the average climatic 548 winds while Fig.7B presents that formed under the NCEP winds. As seen, the RC plays the 549 dominant role in the transport of oil at the sea surface, at the same time winds make adjustments 550 to the general distribution of oil droplets in both cases. While under smoothed climatic monthly 551 winds the oil slick following the general direction of the RC flows to the southwest (Fig 7A), 552 more chaotic daily NCEP winds spread oil over a wider area so that some amounts of oil are 553 trapped by mesoscale elements of the Black Sea circulation leading to the formation of multiple 554 filaments in the oil slick (Fig 7B). Interestingly, some filaments caused to split the oil slick and 555 force one branch to move southwest down to Turkey coast. Both experiments indicate that some 556 amount of oil are entrained by the SAE and accumulated along its periphery. As to the 557 contamination of beaches and the bottom, the model predicts, in the first case, only 8 and 7 tons 558 of beached and deposited oil, respectively, while, in the second case, in the result of stronger 559 wind effect 166 and 176 tons of oil are expected to be on beaches and at the bottom, respectively.

560 In both cases, beached oil contaminated the eastern coast of the Crimea including its southern 561 tip.

\section{Scenario 2}


563 The next scenario may be referred to as one of the most hazardous events for the marine

564 environment when the oil plume rising toward the sea surface is likely to be captured by coastal

565 eddies approaching the plume. Accumulation of oil droplets inside of the convergence zone

566 created by the anticyclonic eddy and its movement along the coast may present a severe threat

567 not only to the marine environment but also vulnerable beaches. To scrutinize a combined effect

568 of the basin-scale RC, winds, and local nearshore eddies, an often-observed event when the

569 CNAE moving northwestward along the northeastern Caucasian coast to the Crimean peninsula

570 is considered. Understanding behavior of the rising oil droplet plume requires knowledge of its

571 interaction with underwater crossflow and surface current as well as an influence of ambient

572 water density on the spreading of oil droplets. Therefore, first of all, features of local dynamics

573 of the Caucasian and Crimean coastal waters will be considered to elucidate how it may affect

574 the oil plume behavior. For this, pre-described with the Die2BS mean velocity, V, temperature,

$575 \mathrm{~T}$, and salinity, S fields for the period of favorable for the generation of Caucasian eddies

576 (winter) were chosen.

$577 \quad$ Figure 8 shows sequential snapshots of the simulated sea surface height and streamlines on

578 Days 30, 40, 45 and 50 (Fig. 8A-D) of year 24. As seen, there is the well-pronounced chain of

579 coastal anticyclonic eddies, including the dominant SAE southwest of Crimean peninsula,

580 embedded in the Rim Current, and the cyclonic vorticity zone in the central part of the Black Sea

581 divided into the western, central and eastern gyres. Figure $\mathbf{8 A}$ indicates that, by Day 30, the

582 well-pronounced CNAE has been formed along the Caucasian coast southeast of Novorossiysk.

583 According to the prehistory, the generation of the CNAE has been triggered by a large

584 offshore protrusion of the Rim Current in the region between Sochi and Sukhumi. As the CNAE

585 was shifting towards the Kerch Strait, it was growing during the following 15 days and then

586 protruded into RC's cyclonic meander. In result of squeezing of the peripheral southern flank of

587 the cyclonic meander and its detachment (light blue shading) by the end of oil experiment (Fig.

588 8D) a dipole structure of circulation consisting of the CNAE and the cyclonic eddy (CE) was

589 formed right over the deepsea oil source. Such evolution of CNAE above the source will strongly

590 affect the behavior of the rising oil plume, surfacing oil droplets and, hence, the transport and

591 transformation of the oil slick.

592 According to the scenario 2, the oil source was launched from Day 30 of simulated year 24.

593 For the period of the experiment, average NCEP winds over the point of oil release are presented 
594 in Fig. 9A. As seen, moderate unsustainable winds ranging from 1 to $7 \mathrm{~m} \mathrm{~s}^{-1}$ were blowing 595 periodically from the southern and northern directions.

596 For two initial days of oil experiment (Fig. 10A), the surfaced oil slick moving

597 northwestward and finally approached the Crimean coast despite the competing action of wind

598 drift caused by southwesterly wind and the local loop of the Rim Current directed to the

599 southwest. For the next two days, the strong northwesterly wind was turning to the northeast and

600 then, for two days, it started to blow from the southwest with speed dropped to about $2 \mathrm{~m} \mathrm{~s}^{-1}$.

601 Such sequence of winds and local circulation has led to the deflection of the oil slick to the 602 southwest and its dragging along the eastern Crimean coast.

603 The beginning of the following 5-day period of the experiment (Fig. 10B) was characterized 604 by strengthening of southeasterly wind, which later changed to the westsouthwesterly wind of 605 about $4 \mathrm{~m} \mathrm{~s}^{-1}$ and then turned to strong northwesterly winds of about $7 \mathrm{~m} \mathrm{~s}^{-1}$. That sequence of 606 the winds in synergy with the RC action deflected the oil slick to the eastern coast of Crimea.

607 Farther, the oil slick was pressed against the eastern Crimean coast that results in intense oil 608 beaching at the southeastern and southern Crimean coasts. By the end of Day 40, the front-end of 609 the oil slick propagating southwestward was involved in the anticyclonic rotation due to its 610 capture by the SAE.

611 For the period from Day 40 to 45 , winds varied from 3 to $7 \mathrm{~m} \mathrm{~s}^{-1}$ and blew mostly from the

612 north. By Day 45 (Fig. 10C), the sequence of the winds caused the oil slick to move

613 southwestward to the Crimea. As the result of combined effects of the RC, SAE and wind

614 variability, the slick split twice, as was shown by the marks 4 and 5. The branch-1 of the oil slick

615 was originated as a result of the bifurcation of the RC (mark 4) and propagation of oil with

616 cyclonic current flowing along the western coast of the Crimea. The branch-3 was originated by

617 oil flowing with the mainstream of the RC and its deformation by the SAE. After bifurcation

618 (mark 5), the branch-2 was involved in the rotation with the SAE while the branch-6 kept

619 propagating to the south following the RC.

620 During Days 45-50 (Fig. 10C, D), winds kept blowing from the northern sectors and their

621 speed varied from 3 to $8 \mathrm{~m} \mathrm{~s}^{-1}$. As a result of the capture of surfaced oil by the CNAE situated

622 over the point of the oil release, a considerable amount of oil accumulated in the area south of

623 the Kerch Strait and Anapa. The accumulation of oil inside the convergent zone generated by the

624 CNAE led to exhaustion of delivering oil at the eastern coast of the Crimea. therefore, by the end 
625 of the experiment, the oil slick has broken into three main parts: 1) oil captured by the CNAE; 2)

626 remnants of the oil spill stretched along the eastern coast of the Crimean peninsula resulting in

627 beaching and depositing and 3) oil penetrated into and/or trapped by the SAE and. Some amount

628 of oil entrained in the RC kept propagating downstream bypassing the SAE. During the entire

629 period of the experiment, the front-end of the oil slick reached $28.5^{\circ} \mathrm{E}, 42.5^{\circ} \mathrm{N}$, i.e., south of

630 Kaliakra peninsula (Bulgaria).

631 Predicting contamination of shorelines

632 Generally, the arrival of oil on the shore is the first indication of an offshore oil pollution

633 accident. Depending on the quantity of oil involved, a clean-up response may have to be

634 organized to remove the oil and to prevent it remobilizing and affecting sensitive areas nearby.

635 That is why a reliable early prediction and estimation of the extension of a pollution zone is the

636 important issue in determining the appropriate scale of clean-up operations to be planned.

637 However, the proximity of the offshore exploration drilling site to the Caucasian and Crimean

638 beaches, in case of an accidental oil blowout, allows only very little time to react and prepare for

639 the clean-up operations. So that any accidental oil spill may cause extreme impacts on the local

640 marine ecosystems and shorelines with negative long-term consequences.

641 To assess the scale of shoreline contamination, the behavior of the oil slick resulting from

642 the surfacing of the deepwater oil plume in the experiment under scenario-2 was examined. The

643 successive phases of the oil slick development and distribution of $\log 10(\mathrm{C})$ are presented in Fig.

644 11, in which the coastline contaminated by oil is marked with the magenta color. During the first

6455 days (Fig. 11A), the oil slick flowing with the cyclonic RC was spreading southwestward

646 under an influence of winds. There was no indication of oil beaching yet during that period.

647 Within the following 5-day period (Fig. 11B), the meandering RC along with the wind action

648 turned the slick in direction to the Crimean coast that caused the intense beaching and depositing

649 of oil. During that period, the coastline from Feodosiya to Sevastopol was predicted to be

650 completely covered by oil.

651 In the 40-45 Day period (Fig. 11C), the changing of the wind direction and meandering of

652 the RC turned the spill slightly offshore albeit it still remained to be attached to the southeastern

653 tip of the Crimean peninsula and kept contaminating the shore and bottom.

654 During the 45-50 Day period (Fig. 11D), the CNAE slowly traveling westward has passed

655 above the site of the oil release causing the capture of oil by the eddy and intense accumulation 
656 of oil inside of it. The extension of the oil-contaminated area would result in delivering a large

657 amount of oil onto the shore near the Town of Anapa, the well-known summer children's

658 recreation area at the Black Sea coast. Another vulnerable area to be contaminated is the eastern

659 coast of the Crimea between the towns of Kerch and Feodosiya.

660 This experiment has revealed a key role played by the CNAE in the spreading of oil

661 pollution when it passes above the oil release site. The approaching CNAE intensively captures

662 rising oil droplets due to the convergent circulation created by the anticyclonic near-shore eddy,

663 causes to the isolation of the oil slick core from the open sea and, thus, intensifies further oil

664 accumulation over the blowout site. Such a highly "oiled" eddy being expanded and transported

665 near the coast will massively contaminate the Caucasian and Crimean beaches.

666 Figure 12 summarizes the oil mass balance as a history of the 20-day continuous oil release.

667 Here, red dots denote total oil spilled, blue asterisks indicate oil mass naturally dispersed

668 throughout the water column, green diamonds show oil evaporated while the oil remained

669 beneath the thin evaporative surface layer $\left(\mathrm{z}_{\mathrm{ev}}\right)$ is presented by light green triangles. Mass of

670 surfaced oil is presented by black dots. Amounts of oil deposited on the bottom and discharged

671 onto the coastline (beached) are shown by yellow squares and magenta dots, respectively. Note

672 that last three components of oil balance indicated by asterisks correspond to values shown at the

673 right ordinate. As simulations revealed, the contamination of the coastline and bottom began in 8

674 days after the oil release. Farther, the beached and deposited oil was rapidly increasing by the

675 day 16, after that the oil mass remained practically unchanged. By the end of the experiment,

676 about 2,100 and 2,200 tons of oil was beached and settled at the bottom, respectively. The mass

677 of evaporated oil reached about 12,000 tons by end of the experiment. As also seen, during the

678 experiment the mass of evaporated oil was growing with the time, reflecting the process of

679 continuous spilling of oil and its rising toward the sea surface, where the light fractions of oil are 680 able to evaporate.

681 Interestingly, the mass of oil at the surface, i.e., within the model thin sub-surface layer of

682 evaporation $\left(\mathrm{z}_{\mathrm{ev}}=0.1 \mathrm{~m}\right)$, was only 5,500 tons $(5.6 \%)$ compared to the total released oil of 96,000

683 tons. The total mass of oil spreading beneath the sea surface was about 80,000 tons, among

684 which the mass of oil dispersed within the active $50 \mathrm{~m}$ surface layer was about 75,000 tons while

685 only 5,000 tons were distributed in the lower column of the plume. 
686

687

688

689

690

691

692

693

694

695

696

697

698

699

700

701

702

703

704

705

706

707

708

709

710

711

712

713

714

715

716

Table 1 lists the mass balance of the spilled oil components over a 20 day period at the indicated time. The table lists the \% weight relative to total mass spilled, as is shown by the red curve in Fig. 11. Rising toward the sea water surface, the light component of oil spreads at the surface and light-end hydrocarbons (most volatile components) evaporate to the atmosphere. As seen, the mass of the evaporated oil increases with the time reaching $12.5 \%$ at the end of the experiment. As was mentioned above, the evaporation of oil comes out from the thin $(0.1 \mathrm{~m})$ layer within which the mass of oil also increases and reaches $4.6 \%$ by the day 20 . The mass of dispersed oil, which is conventionally determined as total oil mass distributed from beneath "evaporative" layer to the bottom, decreases with the time down to $79.1 \%$ by the end of the experiment. Light oil fractions that reach the shoreline can become stranded ashore (beached).

The amount of beached and deposited oil started to grow from the day 7 and reached, by the day 15 , maximum of $3.1 \%$ and $3.3 \%$, respectively. Dispersed oil is considered to be deposited when it reaches the bottom; in the model, this amount is counted separately from the beached oil. Interestingly, after reaching maximum both beached and deposited components of oil mass tend to decrease despite their absolute values, in this period, slightly grows (cf. Fig. 12). It is certain to be associated with the CNAE approaching, which captures oil and detains it inside the eddy.

\section{DISCUSSION}

When considering the results of this study, its limitations should be kept in mind. In particular, this study focused on only two scenarios conducted in winter albeit it is clear that for different seasons more intriguing results of modeling deepwater oil plumes might be obtained. Moreover, results will also depend significantly on initial conditions. For example, a use of different winds in two experiments under scenario-1 led to significant changes in the behavior of the oil slick and modified the final distribution of oil. On the other hand, a use of the same NCEP winds in scenario-1 and -2 but different time of release led also to tremendous dissimilarity in the behavior of the oil slick and different grade of shore contamination. The goal of this study was to illustrate the sensitivity of the coupled model to predict the influence of mesoscale eddies on the transport of oil pollution resulting from a possible accidental deepwater blowout in the Black Sea. It should be emphasized that the present paper focused on methodology, rather than aiming at accurate oil spill predictions, because of large uncertainties in a deepsea oil spill blowout that may happen. Such uncertainties may be eliminated and exact parameters are specified only during the period of a real event. Nevertheless, the model can qualitatively predict what reaction 
717 and consequences should be expected in case if CNAE(s) will approach the oil slick resulting

718 from the deepwater blowout. Besides, the coupled oil spill model allows assessing the oil mass

719 balance and inferring those components related to contamination of the shore and bottom.

720 Estimating bottom contamination is also important as like as the shoreline pollution since due to

721 weathering and dispersion processes some amount of oil may sink and deposit at the bottom.

722 Deposited oil materials, often existing in the form of tar-balls, may be churned up form shallow

723 coastal waters by future storms and blown ashore as was happen when hurricane Isaac (Dietrich

724 et al., 2014) passed over the GoM in 2 years after the BP DWH accident in 2010.

\section{CONCLUSION}

726 In the Black Sea, the advection of near-shore anticyclonic eddies is regarded as one of the most

727 effective mechanisms of horizontal water/pollution transport and exchange between coastal zone

728 and the open sea, and, thus, can be considered as the key mechanism of self-cleaning the coastal

729 zone of the sea. However, such mechanism can work effectively only in cases, when the Rim

730 Current is unstable and nonpersistent. Otherwise, near-shore anticyclonic eddies prove to be

731 trapped between the shore and the persistent Rim Current jet, so that any contaminants captured

732 by the CNAEs are to be accumulated and transported along the coastline leading to significant

733 contamination of coastal waters and beaches. Such negative role of CNAEs has been scrutinized

734 in simulations with a deepwater oil blowout conducted in a prospective region for oil drilling in

735 the Black Sea.

736 The present work illustrates what may happen in the case, when the Caucasian anticyclonic

737 eddy are formed in the region between Sukhumi and Sochi moves along the Caucasian coast and,

738 being squeezed between the Rim Current and coast, will arrive in the near-shore region south of

739 the Kerch Strait. In this particular case, the CNAE will entrain oil coming from the deepwater

740 source, accumulate and deliver it on the coast along a track of the CNAE.

741 As satellite observations indicate, sometimes a CNAE can suddenly stop on its way along

742 the Caucasian coast (it often happens in the region between Novorossiysk and Sochi), and,

743 rapidly growing, protrudes into the $\mathrm{RC}$ creating a large anticyclonic system consisting of an

744 anticyclonic meander and CNAE. Such system was revealed to be unstable and, as satellite

745 observations (Zatsepin et al., 2003; Korotaev et al., 2003) and numerical simulation (Korotenko,

746 2017) evidenced, protruding deeply into meander. It leads to the rupture of the meander by the

747 eddy and, thus, detachment of the latter from the RC. Such sequence of events is certain to have 
748 a great impact on the behavior of the submarine oil plume and planned to be investigated in the

749 future works.

$750 \quad$ Acknowledgments

751 The author is grateful to D. Dietrich and M.J. Bowman for their help with the hydrodynamic

752 model setup and tuning, as well as 3 anonymous referees for their valuable remarks and

753 suggestions that significantly helped to improve the paper.

754 REFERENCES

755 Akhmetzhanov AM, Ivanov MK, Kenyon NH, Mazzini A (eds.) 2007. Deep-water cold seeps,

756 sedimentary environments and ecosystems of the Black and Tyrrhenian Seas and Gulf of

757 Cadiz. Preliminary results of investigations during the TTR-15 cruise of RV "Professor

758 Logachev.” June-August, 2005. IOC Technical Series No. 72, UNESCO.

759 Camilli R. Reddy CM, Yoerger DR, Van Mooy BAS, Jakuba MV, Kinsey JC, McIntyre

760 CP, Sylva SP, Maloney JV. 2010. Tracking hydrocarbon plume transport and biodegradation

761 at Deepwater Horizon. Science 330: 201-4 DOI: 10.1126/science.1195223.

762 Caratelli EP, Dentale F, Reale F. 2011. On the effects of wave-induced drift and dispersion in

763 the deepwater horizon oil spill. In Liu Y, MacFadyen A, Ji Z.G, Weisberg RH, eds.

764 Monitoring and Modeling the Deepwater Horizon Oil Spill: A Record-Breaking Enterprise,

765 Geophysical. Monograph Series 195:197-204. AGU. Washington DC

766 DOI:10.1029/2011GM001109.

767 Chen F, Yapa P. 2007. Estimating the oil droplet size distribution in deepwater oil spills,

768 Journal Hydraulic Engineering 133:197-207 DOI:10.1061/(ASCE)0733-

769 9429(2007)133:2(197).

770 Dasanayaka LK \& Yapa PD. 2009. Role of plume dynamics phase in a deepwater oil and gas

771

772 release model. Journal of Hydro-Environment Research 2: 243-253

773 doi:10.1016/j.jher.2009.01.004.

Dietrich DE, Lin CA, Mestas-Nunez A, Ko DS. 1997. A High Resolution Numerical Study of Gulf of Mexico Fronts and Eddies. Meteorology and Atmospheric Physics 64(3-4):187-201 DOI: https://doi.org/10.1007/BF01029692.

Dietrich DE, Bowman MJ, Korotenko KA, Bowman MHE. 2014. Oil Spill Risk Inc. ISBN 1119027918, 9781119027911 
779

780

781

782

783

784

785

786

787

788

789

790

791

792

793

794

795

796

797

798

799

800

801

802

803

804

805

806

807

Egorov VN, Polikarpov GG, Guli SB, Artemov YG, Stokozov NA, Kostova SK. 2003.

Present-day views on the environment-forming and ecological role of the Black Sea seeps (in Russian). Marine Ecology 2:5-26.

EMODNET Black Sea Checkpoint, Available at http://emodnet-blacksea.eu (accessed 13 April 2018).

Ergün M, Dondurur D, Cifci G. 2002. Acoustic evidence for shallow gas accumulations in the sediments of the eastern Black Sea. Terra Nova, 14: 313-320 DOI: 10.1046/j.13653121.2002.00434.x.

Fingas M (ed.) 2017. Oil Spill Science and Technology. 2-nd Edition. Elsevier Inc.

Hénaff ML, Kourafalou VH, Paris CB, Helgers J, Aman ZM, Hogan PJ, Srinivasan A. 2012. Surface evolution of the Deepwater Horizon oil spill patch: Combined effects of circulation and wind-induced drift. Environment Sciences and Technology 46:7267-7273 DOI: $10.1021 / \mathrm{es} 301570 \mathrm{w}$.

Jaoshvily S. 2002. The Rivers of the Black Sea. Technical Rep. No 71. European Environment Agency, https://www.eea.europa.eu/publications/technical_report_2002 71

Johansen O. 2003. Development and verification of deep-water blowout models. Marine Pollution Bulletin 47:360-368 DOI: https://doi.org/10.1016/S0025-326X(03)00202-9

Korotaev G, Oguz T, Nikiforov A, Koblinsky C. 2003. Seasonal, interannual, and mesoscale variability of the Black Sea upper layer circulation derived from altimeter data. Journal of Geophysical Research 108:3122-3132 DOI: 10.1029/2002JC001508.

Korotaev G, Oguz T., Riser S. 2006. Intermediate and deep currents of the Black Sea obtained from autonomous profiling floats. Deep-Sea Research, Part II 53:1901-1910 DOI: https://doi.org/10.1016/j.dsr2.2006.04.017.

Korotenko KA. 2015. Modeling mesoscale circulation of the Black Sea. Oceanology 55:820926 DOI: https://doi.org/10.1134/S0001437015060077.

Korotenko KA. 2016. High-Resolution Numerical Model for Predicting the Transport and Dispersal of Oil Spill in Result of Accidental Deepwater Blowout in the Black Sea. Proceedings of the 26th International Ocean and Polar Engineering Conference. Rhodes. Greece. June 26-July 1, 2016. III:1534-1541 ISBN 978-1-880653-88-3. 
808 Korotenko KA. 2017. Modeling processes of the protrusion of near-coastal anticyclonic eddies

809

810

811

812

813

814

815

816

817

818

819

820

821

822

823

824

825

826

827

828

829

830

831 832

833

834

835

836 through the Rim Current in the Black Sea. Oceanology. 57:394-401 DOI: https://doi.org/10.1134/S0001437017020114.

Korotenko KA, Mamedov RM, Mooers CNK. 2001. Prediction of the dispersal of oil transport in the Caspian Sea resulting from a continuous release. Spill Science and Technology Bulletin 6:323-339 DOI: https://doi.org/10.1016/S1353-2561(01)00050-0.

Korotenko KA, Bowman MJ, Dietrich DE. 2003. Modeling of the circulation and transport of oil spills in the Black Sea. Oceanology 43:367-378.

Korotenko KA, Bowman MJ, Dietrich DE. 2010. High-resolution model for predicting the transport and dispersal of oil plumes resulting from accidental discharges in the Black Sea.

Terrestrial, Atmospheric and Oceanic Sciences 21:123-136 DOI: 10.3319/TAO.2009.04.24.01(IWNOP).

Korotenko KA, Bowman MJ, Dietrich DE, Bowman MH. 2013. Modeling 3-D transport and dispersal of oil plume released during BP/Horizon accident in the Gulf of Mexico in 2010. Journal of Sustainable Energy Engineering 1:85-104 DOI:

https://doi.org/10.7569/JSEE.2012.629504

Korotenko KA, Mamedov RM, Kontar AE, Korotenko LA. 2004. Particle tracking method in the approach for prediction of oil slick transport in the sea: Modelling oil pollution resulting from river input. Journal of Marine Systems 48:159-170 DOI:

https://doi.org/10.1016/j.jmarsys.2003.11.023.

Körber J-H, Sahling H, Pape T, Ferreira C, MacDonald I, Bohrmann G. 2014. Natural oil seepage at Kobuleti Ridge, eastern Black Sea. Marine and Petroleum Geology 50:68-82 DOI: http://dx.doi.org/10.1016/j.marpetgeo.2013.11.007.

Krivosheya VG, Titov VB, Ovchinnikov IM, Moskalenko LV, Skirta AY, Monakhov VV. 2001. New data on the current regime on the shelf of the northeastern Black Sea. Oceanology 41:307-316.

Lardner R, Zodiatis G. 2017. Modelling oil plumes from subsurface spills, Marine Pollution Bulletin 124: 94-101http://dx.doi.org/10.1016/j.marpolbul.2017.07.018

Laverov NP. 2003. Actual Problems of Oceanology. Moscow: Nauka. 
837 Lavrova OYu, Kostianoy AG. 2011. Catastrophic oil spill in the Gulf of Mexico in April-May

838 2010. Izvestiya RAS, Atmosphere and Oceanic. Physics 47(9):1114-1118 DOI:

839 https://doi.org/10.1134/S0001433811090088

840 Li Z, Lee K, King T, Boufadel MC, Venosa AD. 2008. Oil droplet size distribution as a

841 function of energy dissipation rate in an experimental wave tank. Proceedings of 2008-th

842 International Oil Spill Conference. API, Washington DC.

843 Liu YM, MacFadyen A, Ji Z-G, Weisberg RH (eds.) 2011. Monitoring and modeling the

844 Deepwater Horizon oil spill: A record-breaking enterprise, Geophysical. Monograph Series

845 195. AGU. Washington DC DOI: $10.1029 / \mathrm{GM} 195$.

846 Mackay D, McAuliffe C. 1988. Fate of hydrocarbons discharged at sea. Oil and Chemical

847 Pollution 5:1-20.

848 Mariano AJ, Kourafalou VH, Srinivasan A, Kang H, Halliwell GR, Roffer EH, Ryan M.

849 2011. On the modeling of the 2010 Gulf of Mexico Oil Spill. Dynamics of Atmospheres and

$850 \quad$ Oceans. 52:322-340 DOI: https://doi.org/10.1016/j.dynatmoce.2011.06.001.

851 Masutani SM, Adams EE. 2001. Experimental Study of Multi-Phase Plumes with Application

852 to Deep Ocean Oil Spills. Final Report of the U.S. Department of the Interior Minerals

853 Management Service No:1435-01-98-CT-30964.

854 McDonald N. 1998. The decay of cyclonic eddies by Rossby wave radiation. Journal of Fluid

855 Mechanics 361:237-252 DOI:10.1017/S0022112098008696

856 Mityagina MI, Lavrova OYu. 2012. Satellite survey of the Black Sea Coastal zone.

857 International Water Technology Journal 2:65-77.

858 North EW, Adams EE, Schlag Z, Sherwood CR, He R, Hyun KH, Socolofsky SA. 2011.

859 Simulating oil droplet dispersal from the Deepwater Horizon spill with a Lagrangian

860 approach, In Liu YM, MacFadyen A, Ji Z-G, Weisberg RH eds. Monitoring and modeling the

861 Deepwater Horizon oil spill: A record-breaking enterprise, Geophysical. Monograph Series

862 195:217-226 AGU. Washington DC DOI: 10.1029/2011GM001102.

863 North EW, Adams EE Thessen AE, Schlag Z, He R, Socolofsky SA, Masutani SM,

864 Peckham SD. 2015. The influence of droplet size and biodegradation on the transport of

865 subsurface oil droplets during the Deepwater Horizon spill: a model sensitivity study.

866 Environmental Research Letters 10(2): 24016 DOI:10.1088/1748-9326/10/2/024016 
867 Offshore Energy Today. Available at https://www.offshoreenergytoday.com/tag/black-sea 868 (accessed 14 January 2018).

869 Oguz T, Besiktepe S. 1999. Observations on the Rim Current structure, CIW formation and 870 transport in the western Black Sea. Deep-Sea Research, Part I 46:1733-1753.

871 Oguz T, Latun VS, Latif MA, Vladimirov VV, Sur HI, Makarov AA, Ozsoy E,

872 Kotovshchikov BB, Eremeev VV, Unluata U. 1993. Circulation in the surface and

873 intermediate layers of the Black Sea. Deep-Sea Research, Part I, 40:1597-1612.

874 Ostrovskii AG, Zatsepin AG, Soloviev VA, Tsibulsky AL, Shvoev DA. 2013. Autonomous

875 system for vertical profiling of the marine environment at a moored station. Oceanology. 53:

876 233-242 DOI: https://doi.org/10.1134/S0001437013020124.

877 Paris CB, Hénaff ML, Aman ZM, Subramaniam A, Helgers J, Wang D-P, Kourafalou, VH

878 Srinivasan A. 2012. 46 (24):13293-13302 DOI: 10.1021/es303197h.

879 Perry RH, Green DW. 1984. Percy's Chemical Engineers' Handbook, 6th Edition, McGraw 880 Hill Book Co.

881 Poulain PM, Barbanti R, Motyzhev S, Zatsepin A. 2005. Statistical description of the Black

882 Sea near-surface circulation using drifters in 1999-2003. Deep-Sea Research, Part I 52: 2250-

8832274 DOI: https://doi.org/10.1016/j.dsr.2005.08.007.

884 Robinson AG, Rudat JH, Banks CJ, Wiles RLF. 1996. Petroleum geology of the Black Sea.

885 Marine and Petroleum Geology 13:195-223.

886 Socolofsky S, Adams E. 2005. The role of slip velocity in controlling the behavior of stratified 887 multi-phase plumes. Journal of Hydraulic Engineering 131:273-282.

888 Socolofsky SA, Adams EE., Sherwood CR. 2011. Formation dynamics of subsurface

889 hydrocarbon intrusions following the Deepwater Horizon blowout. Geophysics Research

$890 \quad$ Letters 38:L09602 DOI: 10.1029/2011GL047174.

891 Spaulding ML. 1988. A state-of-art review of oil spill trajectory and fate modeling, Oil and 892 Chemical Pollution 4:39-55.

893 Staneva JV, Dietrich DE, Stanev EV, Bowman MJ. 2001. Rim Current and coastal eddy 894 mechanisms in an eddy-resolving Black Sea general circulation model. Journal of Marine 895 Systems 31:137-157 DOI: https://doi.org/10.1016/S0924-7963(01)00050-1.

896 Stoyanov D, Dorogan P, Jelescu S. 1999. The Black Sea contingency planning for marine oil 897 spills In Besiktepe ST, Unluata U, Bologa AS, eds. Environmental Degradation of the Black 
898

899

900

901

902

903

904

905

906

907

908

909

910

911

912

913

914

915

916

917

918

919

920

921

922

923

924

925

926

Sea: Challenges and Remedies, Science Series 2, Environmental Security, NATO, 56:351367.

Visser AW. 1997. Using random walk models to simulate the vertical distribution of particles in a turbulent water column. Marine Ecology Progress Series 158:275-281 DOI:

$$
10.3354 / \text { meps } 158275 \text {. }
$$

Zatsepin AG, Ginzburg AI., Kostianoy AG, Kremenetskiy VV, Krivosheya VG, Stanichny

$$
\text { SV, Poulain P-M. 2003. Observations of Black Sea mesoscale eddies and associated }
$$

$$
\text { horizontal mixing. Journal Geophisical Research 108(C8):3246-3273 DOI: }
$$

$$
\text { 10.1029/2002JC001390. }
$$

Zatsepin AG, Korzh AO, Kremenetskii VV, Ostrovskii AG, Poyarkov SG, Solov'ev DM.

2008. Studies of the hydrophysical processes over the shelf and upper part of the continental slope of the Black Sea with the use of traditional and new observation techniques. Oceanology 48(4): 466-475 DOI: https://doi.org/10.1134/S0001437008040024.

Zheng L, Yapa PD, Chen F. 2003. A model for simulating deepwater oil and gas blowouts- part I: theory and model formulation. Journal of Hydraulic Research 41:339-351 DOI: https://doi.org/10.1080/00221680309499980.

\section{Zhurbas VM, Zatsepin AG, Grigor'eva YV, Eremeev VN, Kremenetsky VV, Motyzhev SV,} Poyarkov SG, Poulain P-M, Stanichny SV, Soloviev DM. 2004. Water circulation and characteristics of currents of different scales in the upper layer of the Black Sea from drifter data. Oceanology 44:30-43.

Yapa PD, Zheng Li. 1997. Simulation of oil spills from underwater accidents I: model development. Journal of Hydraulic Research 35: 673-687 https://doi.org/10.1080/00221689709498401

Zheng Li, Yapa PD. 1998. Simulation of oil spills from underwater accidents II: model verification. Journal of Hydraulic Research 36: 117-134 https://doi.org/10.1080/00221689809498381

Zodiatis G, Lardner R, Solovyov D, Panayidou X, De Dominicis M. 2012. Predictions for oil slicks detected from satellite images using MyOcean forecasting data. Ocean Science 8: 11051115 https://doi:10.5194/os-8-1105-2012 


\section{Figure 1}

The Black Sea bottom topography and composite map of areas, where the presence gas and oil was revealed (modified from Korotenko, 2016).

Red dots indicate origins of oil slicks (Robinson et al., 1996), yellow squares indicate distributions of gas flares (Egorov et al., 2003) and black diamonds indicate gas seepages (Ergün, Dondurur \& Cifci, 2002). The white asterisk inside of the red dot denotes the location of hypothetical deepwater oil blowout over the northwestern edge of the Shatsky Ridge delineated by the green line.

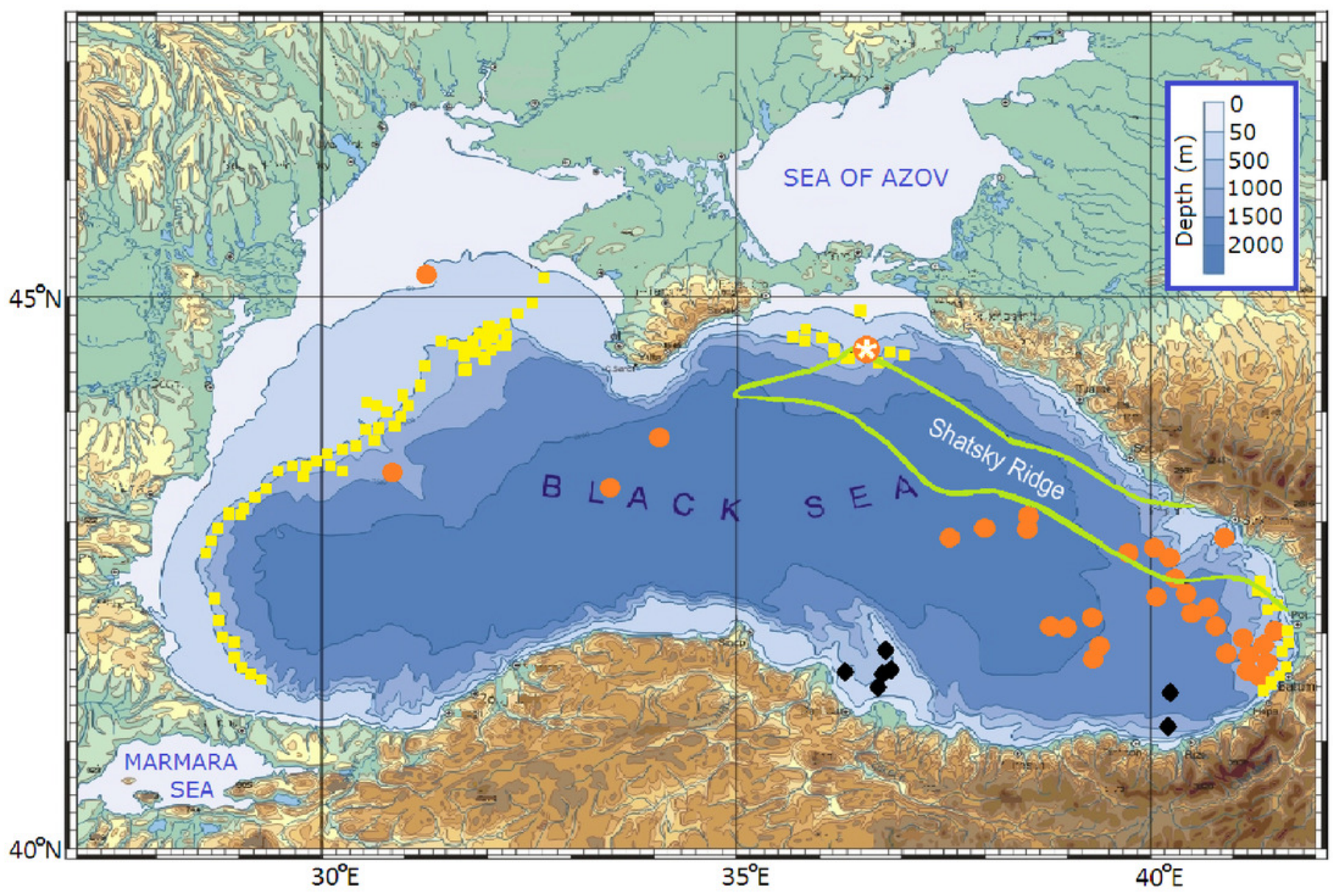


Figure 2

Schematic of the Black Sea circulation (modified from Korotenko, 2016)

1 - mean position of the Rim Current jet; 2 - meanders; 3 - near-shore anticyclonic eddies

(NAEs); 4 - cyclonic eddies (CEs); 5 - Batumi anticyclonic eddy; 6 - Kaliakra anticyclonic eddy;

7- Sevastopol anticyclonic eddy; 8 - Kerch anticyclonic eddy; 9 - quasi-stationary cyclonic

gyres; and 10 - Crimea anticyclonic eddy; and 11 - Bosphorus anticyclonic eddy.

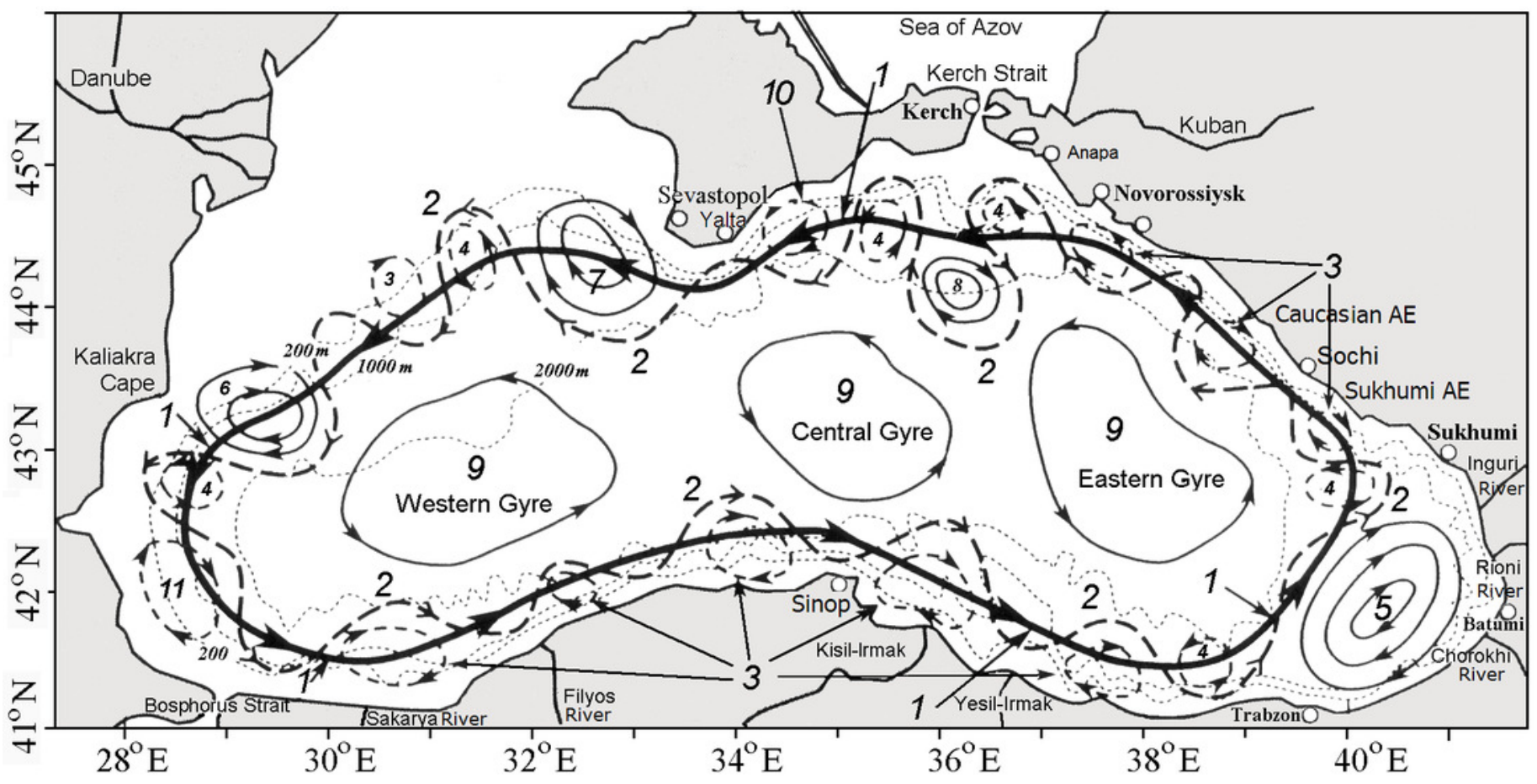


Figure 3

Schematic of principal elements of the Deepwater Oil Spill Model (modified from Korotenko, 2016)

$V, T, S, K_{h}$, and $K_{v}$ denote mean velocity, temperature, salinity, horizontal and vertical viscosities, respectively.

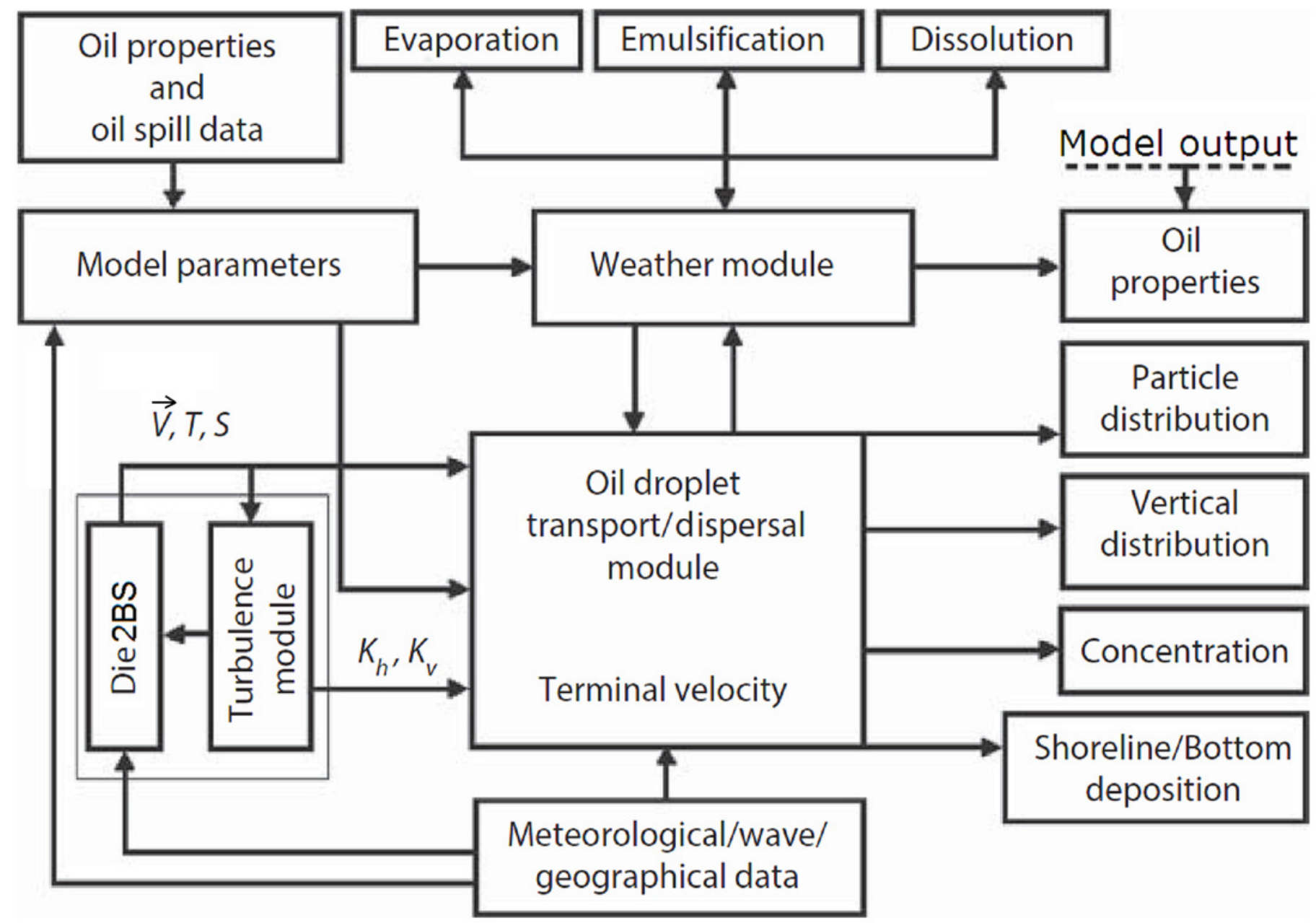


Figure 4

Snapshots of the relative vorticity in the Black Sea on Julian day 80 of model year 24 .

Warm shading denotes positive cyclonic vorticity, cold shading denotes negative anticyclonic vorticity.

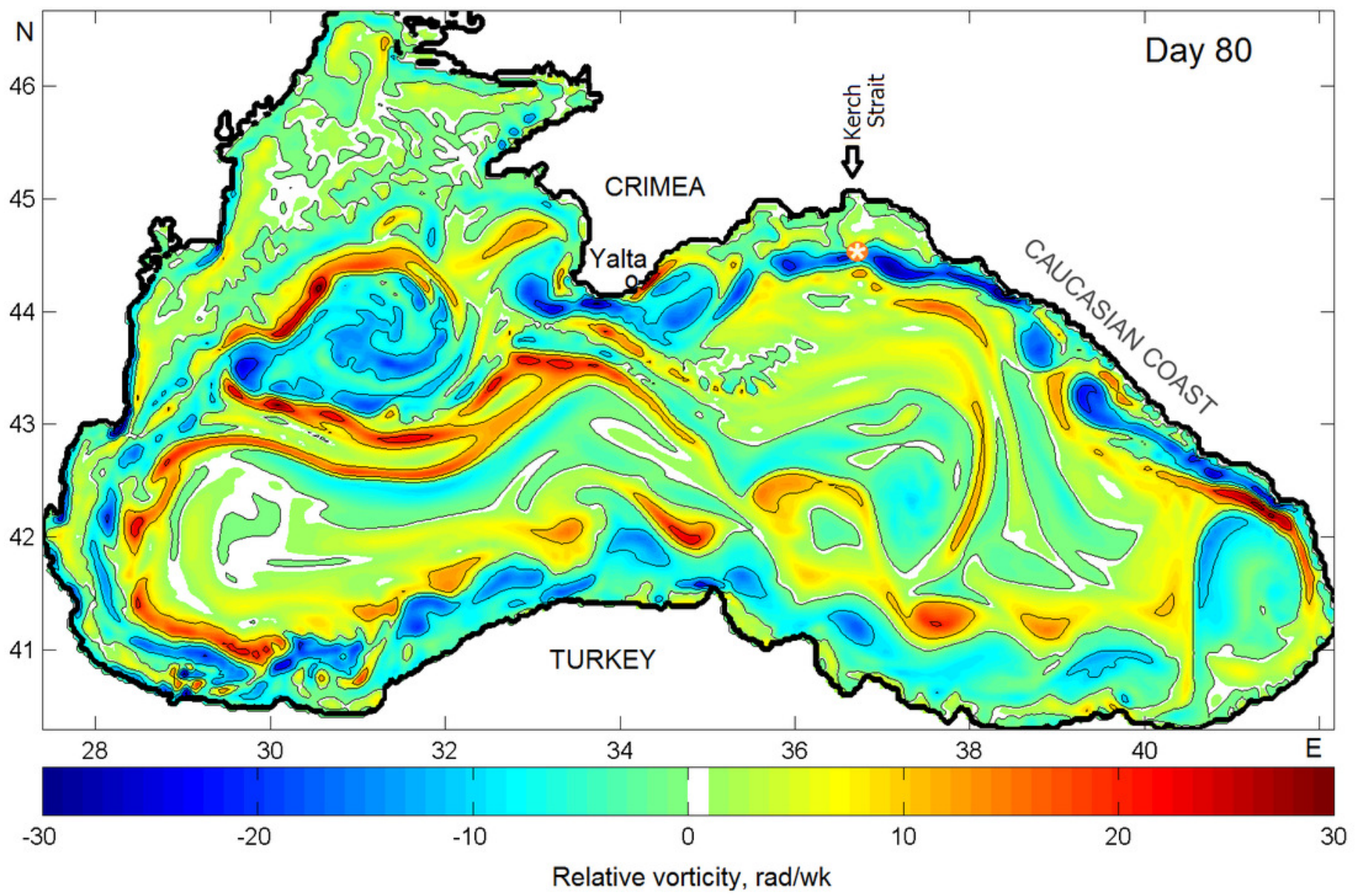


Figure 5

Composite plot of the surface and vertical relative vorticity for the same day as in Fig. 4 . The section was made along $44 \mathrm{~N}$.

Numbers 1-4 are explains in the text.

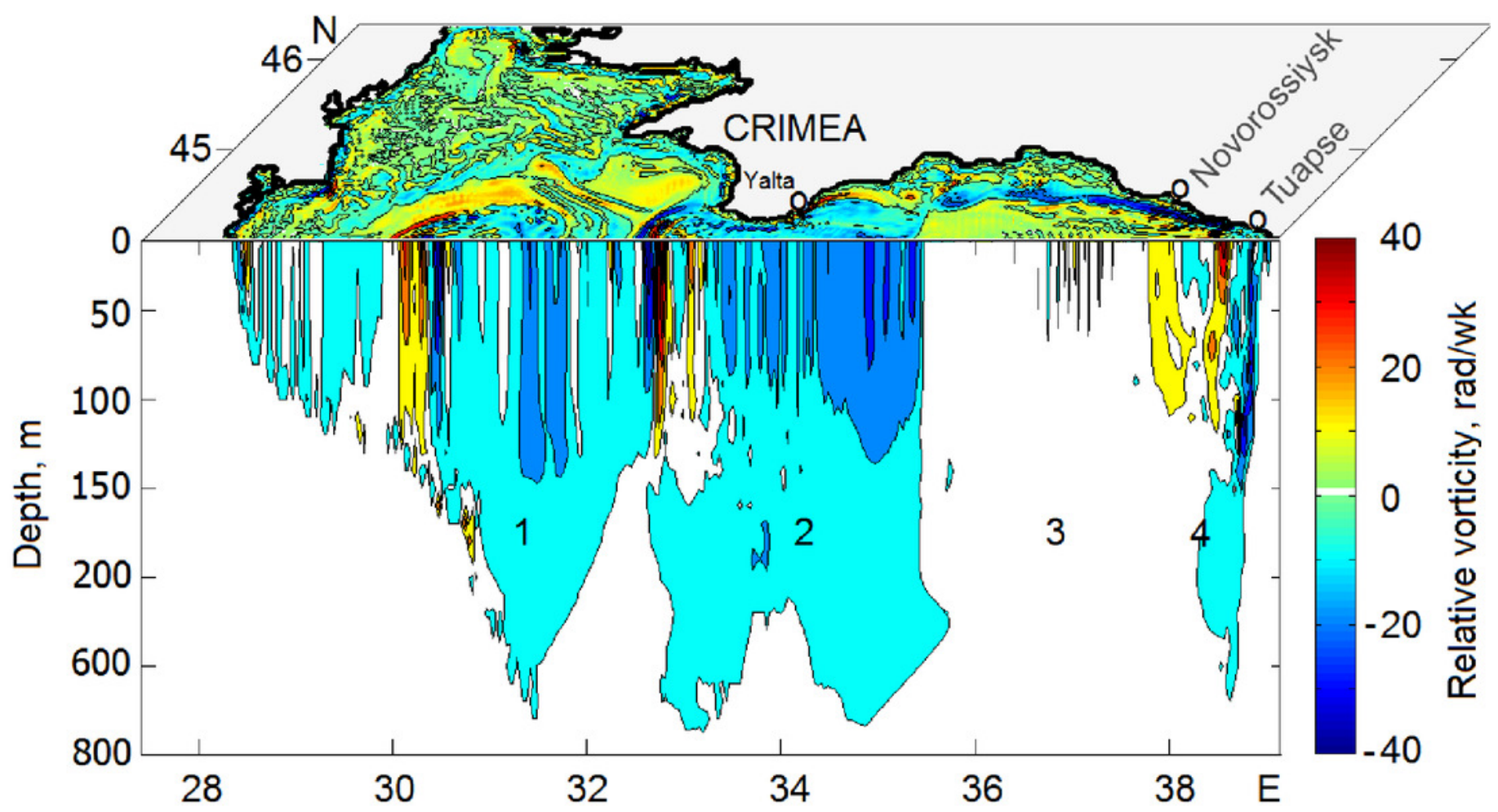




\section{Figure 6}

Inner 3-D structures of the initial stage of a deepwater oil plume in the entire water column (Fig. 6A) and in 250-1000 m layer (Fig. 6B), respectively. Inset (A1) shows a pattern of zonal velocity in the 200-1000 m layer (ADCP measurements). Inset (B1)

Numbers 1-4 in Fig. 6A are explained in the text. Colors of droplets refer to depth range they located: magenta, red, green and blue correspond to 0-250, 250-500, 500-750 and 750-1000 $m$, respectively. Three blue arrows schematically show the Rim Current (RC). N and $E$ indicate north and east directions. 

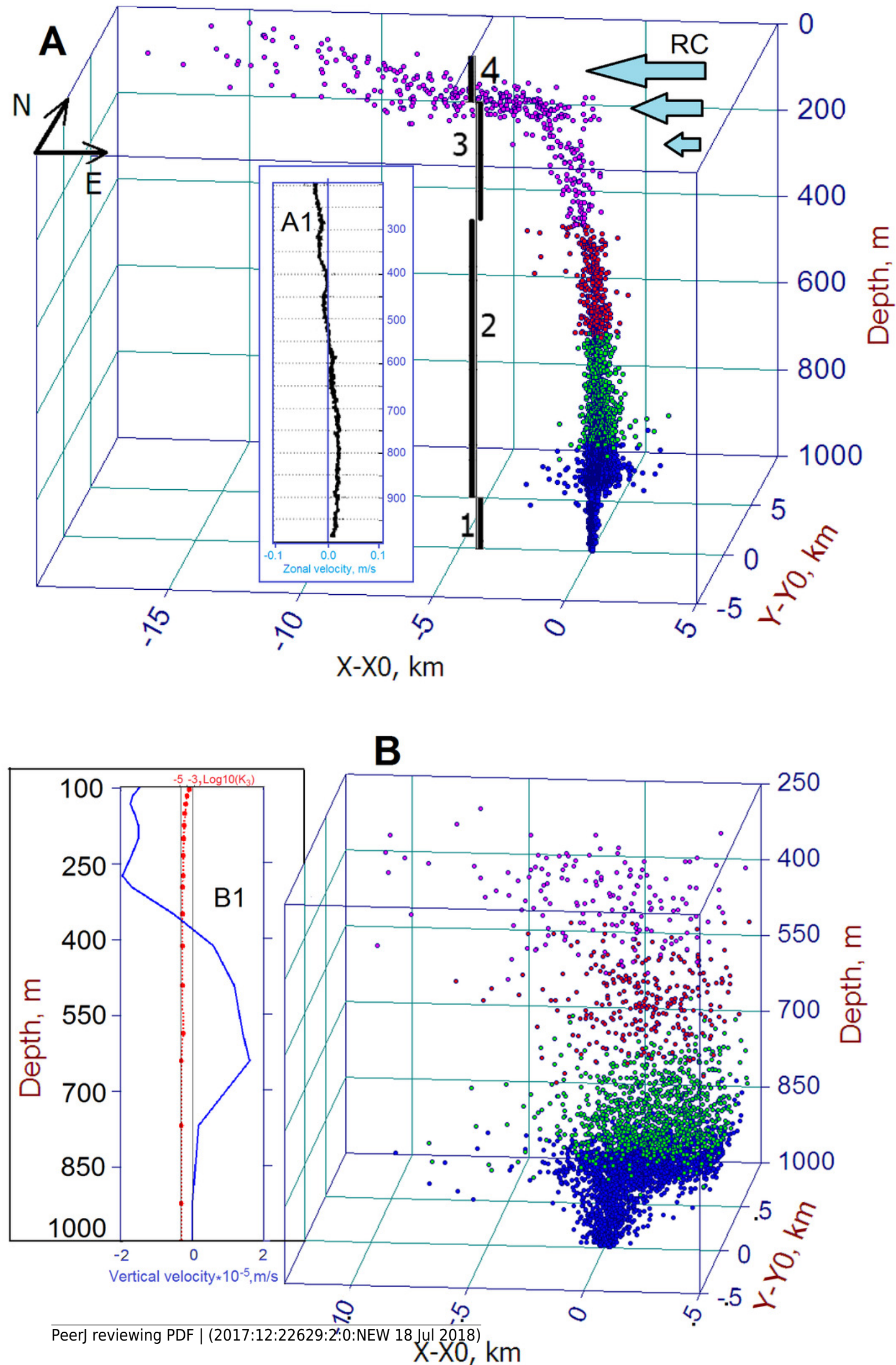


\section{Figure 7}

Final phases of the oil slick development in the 20-day oil blowout experiments under (A) mean climatic winds and (B) daily average NCEP winds.

Sevastopol, Yalta, Sudak, Feodosiya, and Kerch are Crimean towns; Anapa and Novorossiysk are towns at the Caucasian Coast. Arrow indicates the Kerch Strait. 

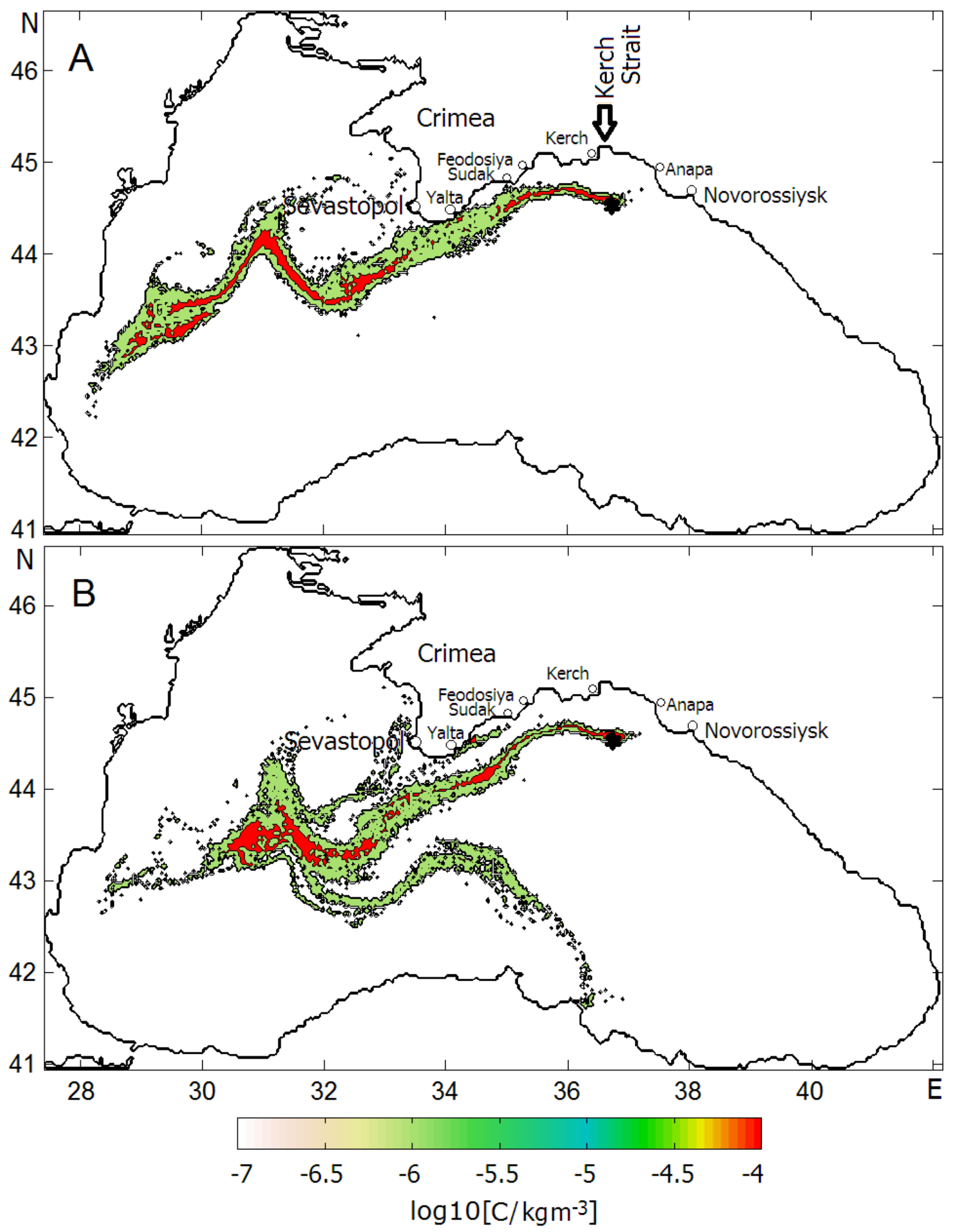
Figure 8

Sea surface height and streamlines indicating the evolution of the Caucasian anticyclonic meander and CNAEs embedded in the Rim Current. Panels (A-D) correspond Julian days: $30,40,45,50$, respectively.

SAE CNAEs denote the Sevastopol and Caucasian anticyclonic eddies, respectively, while CE is cyclonic eddy creating along with the CNAE a dipole structure by the day 50 . The black asterisk indicates the position of the deepwater oil source.
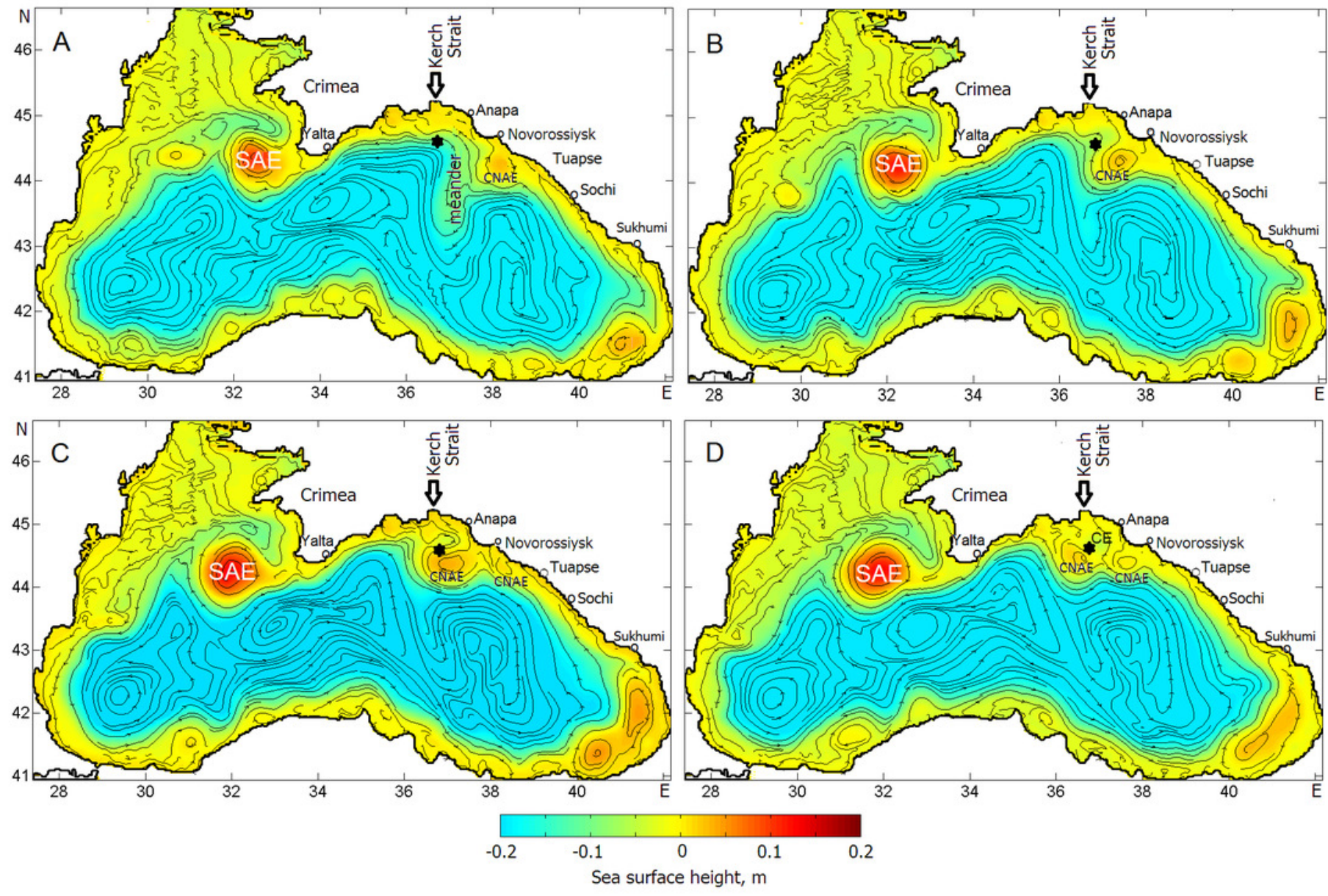
Figure 9

NCEP winds during oil spill experiments.

Each vector indicates the average wind for years 1998 - 2002

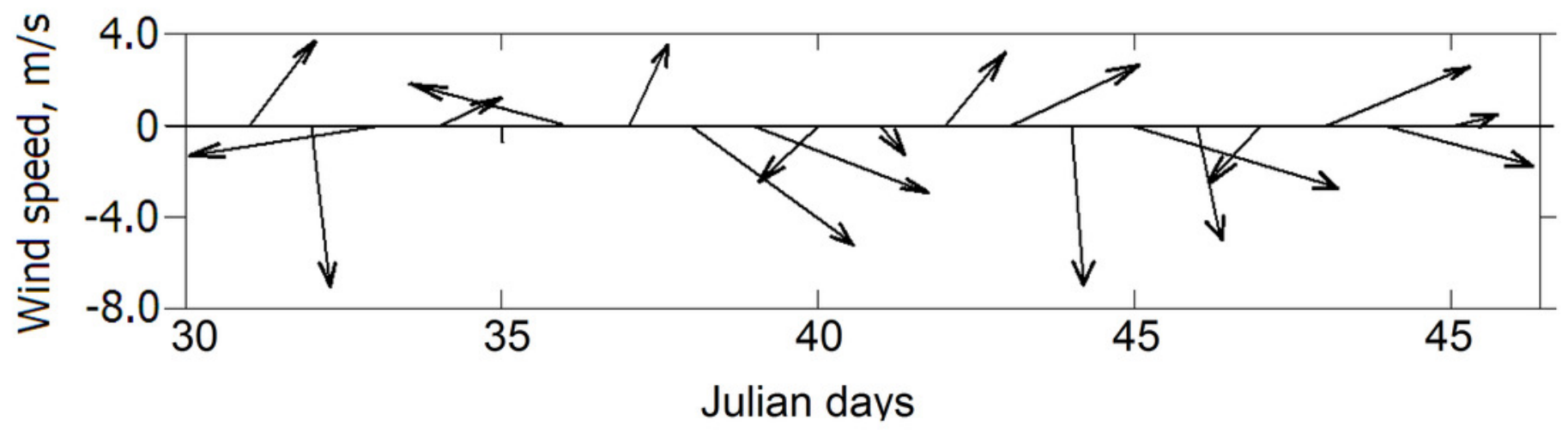




\section{Figure 10}

Successive phases of the oil plume rising from a hypothetic bottom oil source. Horizontal axes indicate the distance from the oil source with coordinates ( $\mathrm{XO}, \mathrm{YO})$.

Distribution of droplets shows the formation of a 3-d oil plume consisting of an underwater part of rising plume and a surface slick spreading under actions of the Rim Current and eddies, which captured oil. Panel (A-D) correspond days of the plume development: 35, 40, 45,50 , respectively. Numbers 1- 6 , in Figure 10C, are described in the text. The droplet color corresponds to that as in Fig. 6 . 

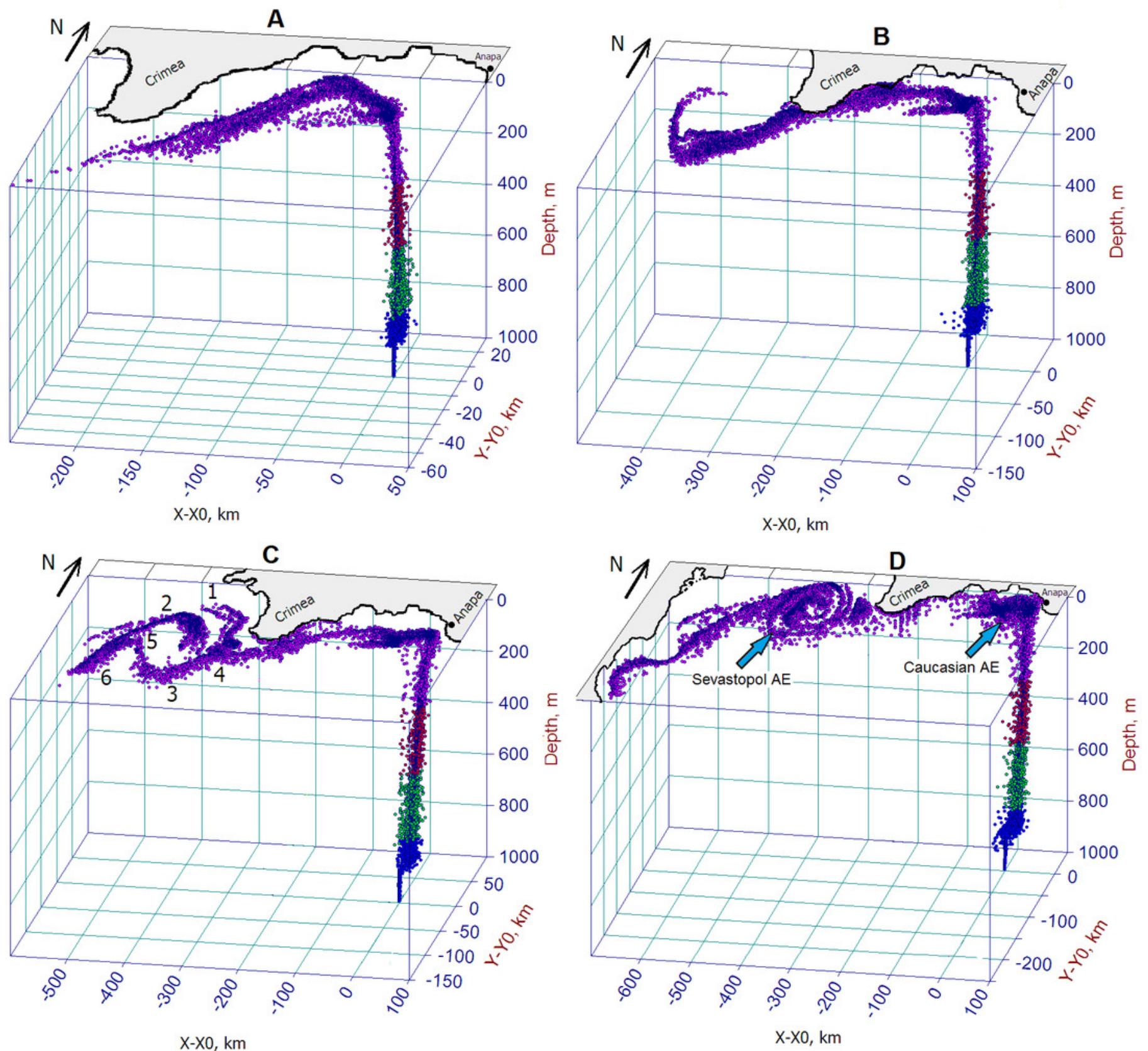
Figure 11

Successive phases of the oil slick development under influences of the Rim Current, NCEP winds and the Caucasian near-shore anticyclonic eddy.

Magenta color denotes coastlines contaminated by oil. Red color indicates the highest level of oil concentrations in the slick. Panels (A-D) correspond Julian days as in Figure 10.

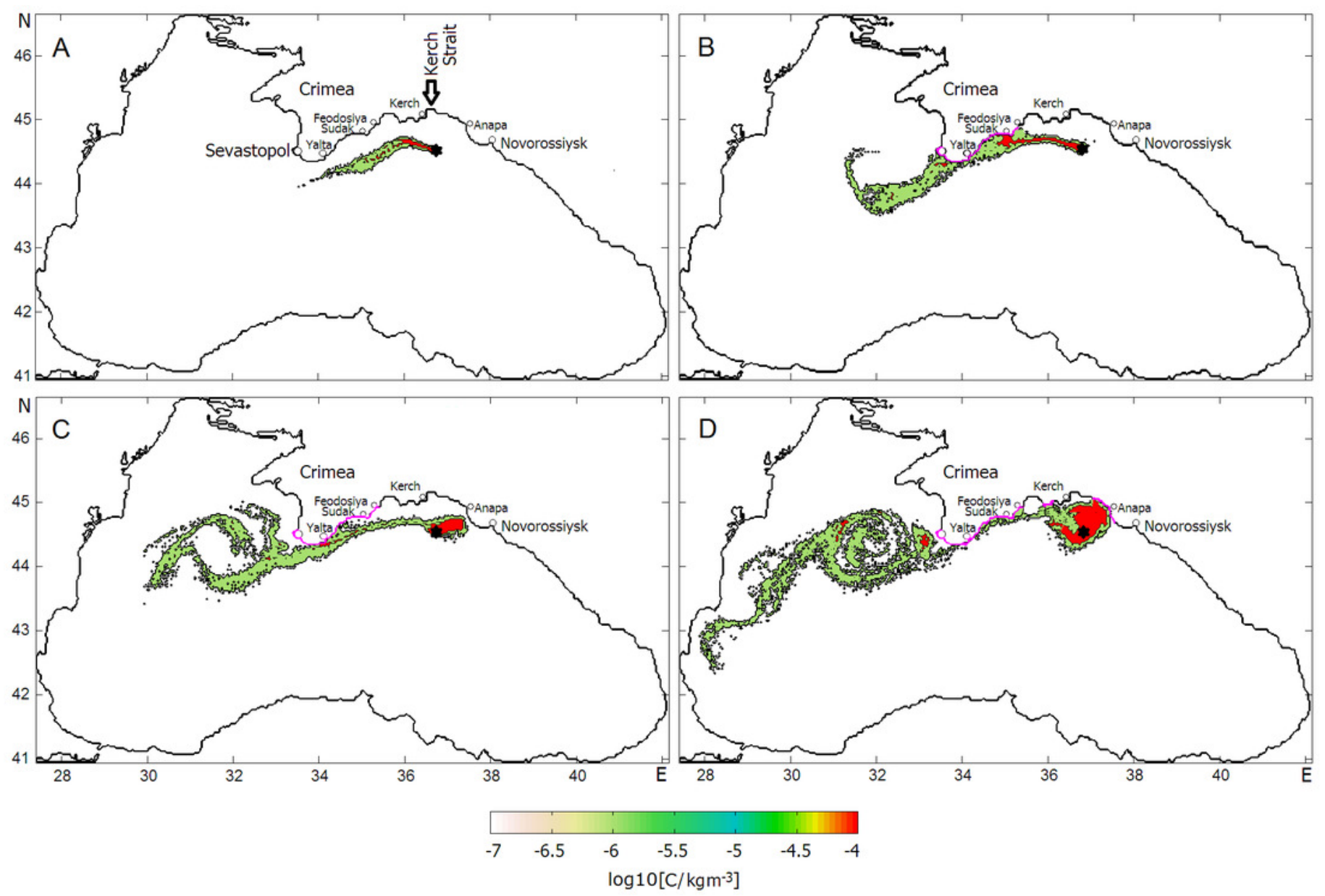


Figure 12

History of the oil mass balance for the scenario 2 .

Oil mass components: oil spilled (red dots); dispersed (blue asterisks); evaporated (green diamonds); surfaced (black dots*); total in the water column (light green triangles); deposited on the bottom (yellow squares*); beached (magenta dots*). The components with asterisks are referred to values on the right $y$-axis

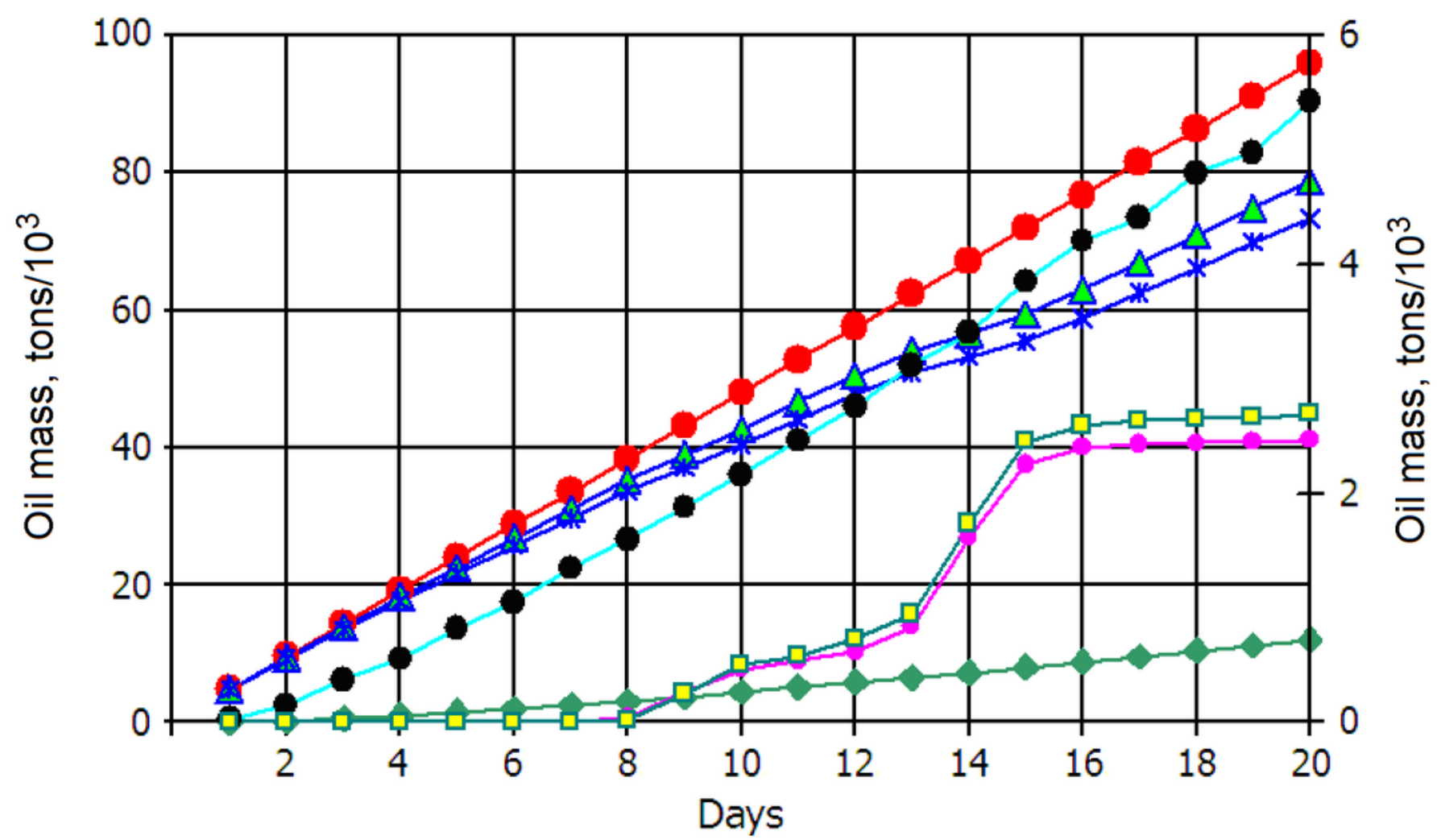




\section{Table $\mathbf{1}$ (on next page)}

Change of mass balance components relative to total oil spilled (in \% Wt) 


\begin{tabular}{|l|l|l|l|l|l|l|l|l|l|l|l|l|l|l|l|l|l|l|l|l|}
\hline Day & 1 & 2 & 3 & 4 & 5 & 6 & 7 & 8 & 9 & 10 & 11 & 12 & 13 & 14 & 15 & 16 & 17 & 18 & 19 & 20 \\
\hline Evaporated & 0.4 & 1.9 & 3.7 & 5.0 & 6.0 & 6.7 & 7.4 & 7.9 & 8.5 & 9.1 & 9.6 & 10.1 & 10.7 & 10.7 & 11.1 & 11.3 & 11.6 & 11.9 & 12.2 & 12.5 \\
\hline Surfaced & 0.5 & 1.5 & 2.5 & 2.8 & 3.4 & 3.6 & 4.0 & 4.1 & 4.3 & 4.5 & 4.6 & 4.7 & 4.6 & 5.0 & 5.35 & 5.4 & 5.4 & 5.5 & 5.4 & 5.6 \\
\hline Dispersed & 99.1 & 96.4 & 93.7 & 92.0 & 90.5 & 89.6 & 88.5 & 87.7 & 85.9 & 84.3 & 83.5 & 82.7 & 79.1 & 79.1 & 77.0 & 76.6 & 76.7 & 76.5 & 76.6 & 76.4 \\
\hline Beached & 0 & 0 & 0 & 0 & 0 & 0 & 0 & 0.1 & 0.6 & 0.9 & 1.0 & 1.0 & 2.4 & 2.4 & 3.1 & 3.1 & 2.9 & 2.8 & 2.6 & 2.5 \\
\hline Deposited & 0 & 0 & 0 & 0 & 0 & 0 & 0 & 0.0 & 0.5 & 1.0 & 1.0 & 1.2 & 1.4 & 2.5 & 3.4 & 3.3 & 3.2 & 3.0 & 2.9 & 2.8 \\
\hline
\end{tabular}

